\title{
Response of Aeroengine with Fusing Design Suffering FBO
}

\author{
Chi Ma $\mathbb{D}$, Wei Chen $\mathbb{D}$, Lulu Liu $(\mathbb{D}$, Zhenhua Zhao, and Gang Luo \\ Jiangsu Province Key Laboratory of Aerospace Power System, College of Energy and Power Engineering, Nanjing University of \\ Aeronautics and Astronautics, Collaborative Innovation Center of Advanced Aeroengine, Nanjing, Jiangsu Province 210016, China
}

Correspondence should be addressed to Lulu Liu; liululu@nuaa.edu.cn

Received 27 April 2019; Revised 20 July 2019; Accepted 21 August 2019; Published 4 November 2019

Academic Editor: Ennes Sarradj

Copyright (C) 2019 Chi Ma et al. This is an open access article distributed under the Creative Commons Attribution License, which permits unrestricted use, distribution, and reproduction in any medium, provided the original work is properly cited.

The loss of fan blades in an aeroengine, or fan-blade out (FBO), is a type of accident that causes a sudden imbalance and large impact load, which leads to complex vibration of a system. To conduct a dynamic analysis of an aeroengine rotor system is an important requirement for relevant departments. The purpose of this paper is to study the dynamic response of a complex dual-rotor system suffering FBO events and the protective effect of the fusing structure on the system. The dynamic model of an aeroengine dual-rotor system is established, and the response of the rotor system is obtained by calculation and analysis. The rear support bearing of the fan has a high reaction force, which may lead to bearing failure. The mechanism of a fusing structure is analyzed, and the results show that the sudden imbalance will produce impact loads on the rotor, resulting in a sharp increase in the vibration amplitude and reaction force, and then, attenuation to steady state. The fusing structure can reduce the amplitude of steady-state rotor vibration and reaction force on the support bearings. However, the transient response of the rotor will increase because of the sudden change in support stiffness.

\section{Introduction}

Aeroengine is a high-speed rotating thermal power machine. Its structure is very complex. Compared with the general mechanical system, its safety and reliability have higher requirements [1]. Due to many factors, such as impact by birds, hail, and other foreign objects, the fan blades may be lost, causing serious accidents of the engine [2]. This engineering problem [3-5] is called fan-blade out (FBO) by many researchers.

When the accident occurs, FBO can not only induce a large imbalance load of the blade disk but also can apply a large impact load and rotor-stator rubbing on the rotor system and containment casing, which will further lead to a complicated vibration response of the whole aeroengine. The aviation safety-management agencies of various countries have established clear requirements for FBO accidents. The United States Federal Aviation Administration (FAA) [6] requires a high-bypass-ratio turbofan engine to pass the blade-loss test. In the event of fan-blade loss, where at least $85 \%$ of the blade mass is lost, the turbofan engine will remain on the mounting rack for at least $15 \mathrm{~s}$ without any noncontainment failures or fire incidents and the turbofan engine will be guaranteed during the longest flight period (the longest flight time required for any aircraft is 3 hours). The European Aviation Safety Administration [7] and China Civil Aviation Administration have made similar demands on this situation.

During the FBO event, the released blade could cause the failure of the engine structure, which can be classified as primary or secondary damage [4]. Primary damage occurs when the liberated blade hits the casing. Moreover, if the case could not contain the blade, the fuselage would then suffer serious safety accidents $[8,9]$. Secondary damage is caused by the destruction of engine structure related to huge imbalance loads caused by the released blade. The unbalancing force will excite the eccentricity of the rotor, which may cause rubbing between the blade tips and the case [10-12] and 
vibration of the rotor system $[13,14]$, as well as damage to the rotor during the deceleration process [15].

During the last several decades, many researchers have paid attention to the FBO event and made many achievements, which can be divided into two areas. One is related to the containment capability of the engine system, and the other is the rotor response excited by the sudden unbalanced loads, which is the main emphasis of this paper. In the early stage, the response of the rotor system under sudden imbalance loads was studied by the FBO test, which is still requested by the relevant authorities today. However, the test is extremely expensive and time-consuming, which is why analytical modeling and numerical simulation become the most economic research methods of predicting the response of the aeroengine. Compared with the traditional steady imbalance problem, the response of the rotor under sudden imbalance loads has a significant characteristic. During the FBO event, the vibration amplitude increases sharply when the blades are released and then decreases gradually to the level of steady response, which is much lower than the transient response. Therefore, many researchers have focused on predicting the peak value of the transient response and the factors that may affect the response.

Kalinowski et al. [16] established the dynamic model of a Jeffcott rotor with a sudden imbalance and investigated the effects of the rotation speed, excitation amplitude, and other factors on the vibration response and the trace of the rotor. However, the Jeffcott rotor, which cannot analyze the gyroscopic moment, is too simplified to represent the actual structure of an engine, so an overhung rotor is a better model to reflect the dynamic characteristics of the jet engine. Raffa and Vatta [17] studied the transient dynamic response characteristics of a biased single disk rotor system. The disk is applied to the rotor system as an external load. The transient motion equation including acceleration term is established by using the transfer matrix method, and the relationship between the lost mass and the transient response is obtained. Ma et al. [18] developed an improved dynamic model of the rotor blade. The finite element method was used to discretize the shaft, and the vibration mode of the rotor-blade system was obtained. By simplifying the casing into a two-degreeof-freedom model, the rubbing problem of single and four blades is studied. Dzenan [14] simulated the vibration response of an overhung rotor to consider the effects of the gyroscopic moment under sudden imbalance loads, and related experiments were carried out to confirm the model. Grapis et al. [19] studied the unbalanced transient response of a dual-disk flexible rotor, analyzed the difference between the natural unbalanced transient response and the sudden unbalanced transient response of the rotor system, and provided a reference for the calculation of the transient response of the rotor. A dynamic model of high-speed flexible rotor system was established by Sinha [20]. The dynamic model can effectively reflect the impact characteristics and vibration response characteristics of the rotor under sudden unbalanced loads. Li et al. [21] established the dynamic model of the rotor-blade system and considered the influence of the nonlinear support at both ends of the rotor-blade system.
The axis considering the gyroscopic effect is simulated as a rotating beam, and the shear deformation is ignored. The effects of normal friction, friction coefficient, damping, and support stiffness on the response of the rotor-blade system are studied. The results show that when the support stiffness is low, the stability of the system is sensitive to the bearing damping. Friction and support stiffness have an important impact on the system instability.

The above research develops the analysis method of rotor system response under blade loss load. However, these research objects are single-rotor systems, which cannot fully reflect the characteristics of the rotor used in aeroengines. The dual-rotor system is widely used in modern aeroengine. Its main structure includes high-pressure rotor, low-pressure rotor, supporting bearing, and intermediate bearing. In a dual-rotor system, there exists coupling between the rotors. It is of great significance and value to study the effect of coupling on the system for analyzing the dynamic characteristics of the aeroengine rotor system and establishing a practical aeroengine dual-rotor model with reasonable simplification and low degree of freedom [22]. Bonello and Minh Hai [23] set up the lumped-parameter model of the reverse rotating dual-rotor system of the aeroengine. By using the transfer matrix method, the dynamic characteristics of the dualrotor system were analyzed and the related conclusions were verified by the experiment. Hai and Bonello [24] established the coupling dynamic model of aeroengine. The finite beam element method is used to establish the model of the rotor and shell, and the nonlinear factors such as rolling bearings and squeeze film dampers are taken into account. The numerical integration method is used to obtain the nonlinear response of the system. Rao et al. [25] established the finite element discrete model of the two-rotor system and analyzed the transient response of the system. By comparing the characteristics of the transfer matrix method and the finite element method, it is pointed out that the finite element method is more advantageous in analyzing the transient response of complex rotors.

The above study shows that the model of the dual-rotor system established by the finite element method can reflect the dynamic characteristics of the rotor system. However, the research on the sudden imbalance load still needs to be improved.

In the FBO event, owing to the high amplitude of the transient response, the reaction force of the bearings, especially those located near the fan, can usually reach a very high value that exceeds the bearing capacity and may lead to failure of the system. Therefore, a safety design structure to reduce structural loading and improve the distribution of the load during FBO events, called fusing structure [26, 27], is used.

When an FBO accident occurs, the reaction force of the rear support of the fan rises sharply. The fused structure can actively make the bearing fail, reduce the load, and ensure that the rotor system does not fail during the deceleration process. The technical approaches are the design of a fusible supporting structure [28] or the design of a variable stiffness support [29]. Given the problem of overloading at the rear fan bearing, the solution is a coordinated 


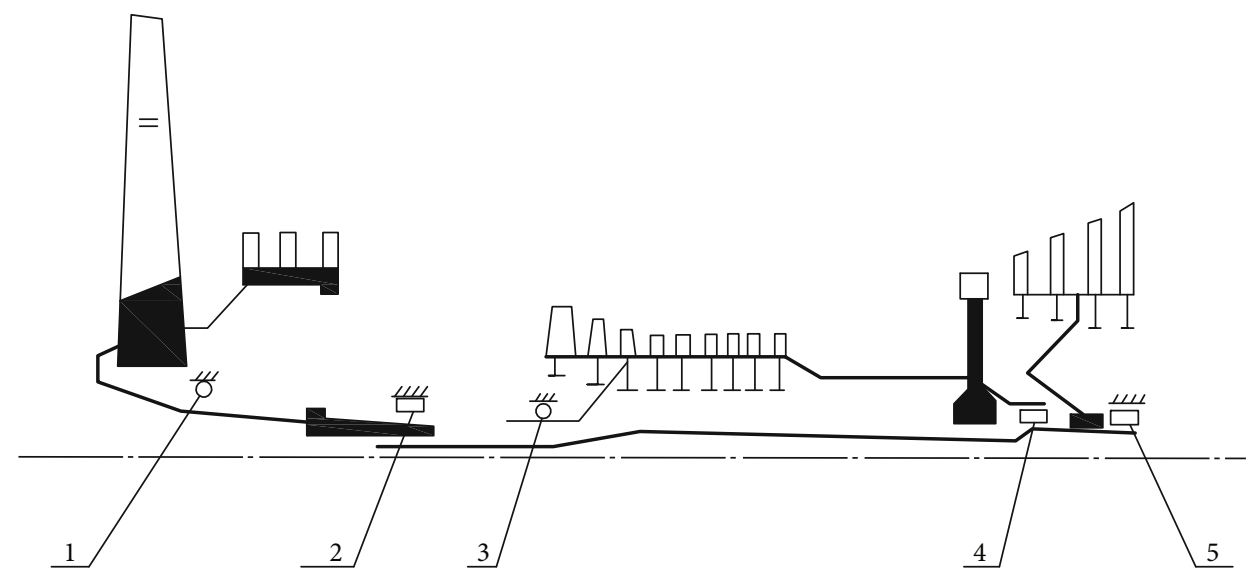

(a) Physical model

\begin{tabular}{|l|l|l|l|l|l|l|l|} 
L1 & L2 & L3 & L4 & L5 & L6 & L7 & L8 \\
\hline
\end{tabular}

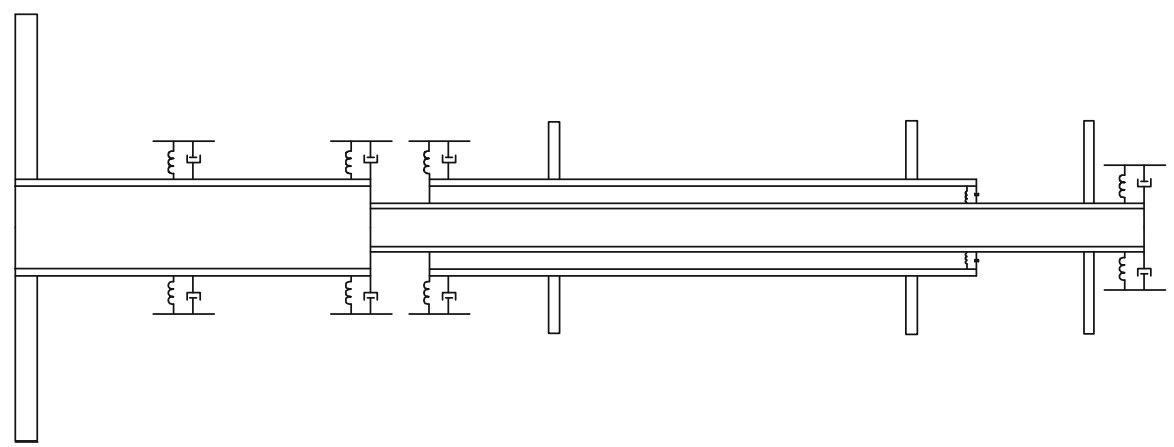

(b) Simplified model

Figure 1: Dual-rotor system model.

design of the bending stiffness and supporting stiffness of the rotor [30].

Generally speaking, the abovementioned research focuses on the design method, without considering the engineering applicability, the structural dynamic characteristics, and the impact on structural safety. For the FBO event of the rotor system, researchers have performed many computational simulations [15] and damage mechanism researches [16] on the dynamic response of the rotor system. Scholars have analyzed the dynamic characteristics of the rotor system with fusing structure in theory and simulation. The whole engine system, including the rotor, bearing, and support, is studied, and a set of theoretical methods with both scientific and engineering values are established.

However, in the existing analysis, the dynamic influence of the transient variation of support stiffness induced by a fusing design is covered by other mechanisms and the potential dynamic problems induced by the fusing design are not well investigated. Previous studies have focused more on the theoretical study of the nonlinear response of the rotor caused by FBO events than on the dynamic response of the actual rotor. Scholars usually use simplified rotor models, such as the Jeffcott rotor, which has a low freedom degree. In fact, the rotor system of the aeroengine usually operates above the first critical speed, and its dynamic characteristics are very complex. Meanwhile, the complex characteristics of loads in FBO events will lead to a more complex system response. In summary, the current research is less focused on the characteristics of the actual rotor system and cannot provide appropriate results for the safety design of aeroengines. The purpose of this paper is to study the dynamic response of an aeroengine dual-rotor system with fusing structure in the event of an FBO event.

A finite element discrete model of the dual-rotor system is established, which considers not only the interaction between the high pressure (HP) rotor and the low pressure (LP) rotor, the structural and mechanical characteristics of the rotors, but also the coupled influence of the sudden imbalance. The vibration responses and the support reaction forces are also discussed. The transient response of the dualrotor system is calculated by the Newmark- $\beta$ integration method. Moreover, the work presented in this paper is aimed at understanding the dynamic influence of the stiffness change caused by the fusing design with mechanism analysis and a series of simulations carried out on an FBO model based on an actual high-bypass turbofan aeroengine.

\section{Dynamic Modeling of the Rotor System}

A practical turbofan engine with a high-bypass ratio is shown in Figure 1. The low-pressure rotor system adopts 0-2-1 support form, and the high-pressure rotor system adopts 1-0-1 
TABLE 1

(a) Geometric parameters of a low-pressure rotor system

\begin{tabular}{lccc}
\hline $\begin{array}{l}\text { Shaft } \\
\text { number }\end{array}$ & $\begin{array}{c}\text { Length } \\
(\mathrm{mm})\end{array}$ & $\begin{array}{c}\text { Internal diameter } \\
(\mathrm{mm})\end{array}$ & $\begin{array}{c}\text { External diameter } \\
(\mathrm{mm})\end{array}$ \\
\hline L1 & 300 & 70 & 80 \\
L2 & 300 & 70 & 80 \\
L3 & 100 & 35 & 40 \\
L4 & 200 & 35 & 40 \\
L5 & 600 & 35 & 40 \\
L6 & 100 & 35 & 40 \\
L7 & 220 & 35 & 40 \\
L8 & 180 & 35 & 40 \\
\hline
\end{tabular}

(b) Geometric parameters of a high-pressure rotor system

\begin{tabular}{lccc}
\hline $\begin{array}{l}\text { Shaft } \\
\text { number }\end{array}$ & $\begin{array}{c}\text { Length } \\
(\mathrm{mm})\end{array}$ & $\begin{array}{c}\text { Internal diameter } \\
(\mathrm{mm})\end{array}$ & $\begin{array}{c}\text { External diameter } \\
(\mathrm{mm})\end{array}$ \\
\hline L4 & 200 & 70 & 80 \\
L5 & 600 & 70 & 80 \\
L6 & 100 & 70 & 80 \\
\hline
\end{tabular}

(c) Parameters of rotating discs

\begin{tabular}{lccc}
\hline Rotating discs & $\begin{array}{c}\text { Mass } \\
(\mathrm{kg})\end{array}$ & $\begin{array}{c}\text { Diameter moment of } \\
\text { inertia }\left(\mathrm{kg}^{*} \mathrm{~m}^{2}\right)\end{array}$ & $\begin{array}{c}\text { Polar moment of } \\
\text { inertia }\left(\mathrm{kg}^{*} \mathrm{~m}^{2}\right)\end{array}$ \\
\hline $\begin{array}{l}\text { Low-pressure } \\
\text { compressor }\end{array}$ & 120 & 4 & 8 \\
$\begin{array}{l}\text { High-pressure } \\
\text { compressor }\end{array}$ & 30 & 1 & 2 \\
$\begin{array}{l}\text { High-pressure } \\
\text { turbine }\end{array}$ & 30 & 1 & 2 \\
$\begin{array}{l}\text { Low-pressure } \\
\text { turbine }\end{array}$ & 60 & 2 & 4 \\
\hline
\end{tabular}

support form. There are intermediate bearings between highand low-pressure rotors, which will cause the vibration responses of the rotors to be coupled with each other. Therefore, it is necessary to establish a dynamic model of the dual-rotor system for analysis. With reference to the rotor system structure, the physical model and simplified model of the dual-rotor system are obtained by simplifying and abstracting.

The simplified dual-rotor dynamic model consists of rotating discs, shafts, and bearings. It consists of four rotating discs, which simulate the rotating parts of high- and lowpressure compressors and high- and low-pressure turbines, respectively, and the shafts are segmented and numbered according to the position of each component.

The dimensions of the high- and low-pressure rotor shaft and the mass of the rotating discs from left to right are listed in Table 1.

The established model meets the following two criteria.

(1) The rotor shaft is composed of the finite element beam model and the rotational inertia; shear defor- mation and gyroscopic moment of the beam are taken into account. Only the lateral bending vibration of the rotor is considered, while the torsional vibration and the axial vibration of the rotating shaft are out of consideration. The high- and low-pressure compressors and the high- and low-pressure turbines are simplified as turntables, which act on the center of a mass in the form of concentrated mass. In addition, the gyroscopic moment of the turntable is taken into account

(2) Bearings are considered as elastic fulcrums, and their elastic support stiffness can be set. The aeroengine dual-rotor-support-casing coupling dynamic model consists of several rotors, supports, and connections. For the rotor system, the finite element method is used to establish the dynamic model. For the support, the discrete lumped mass model is used. Then, the components are coupled through the relationship between the action force and the reaction force. Finally, the numerical integration method is used to analyze the response of the system

\section{Response of a Low-Pressure Rotor System under a Sudden Imbalance Load}

In the case of the FBO event, the most severe response appears at the low-pressure compressor disk. The critical speed is firstly analyzed in ANSYS. In the finite element model, BEAM188 element is used to simulate the rotor shaft, MASS21 element is used to simulate the disk, and COMBI214 element is used to simulate the bearing. The established model meets the requirements such as (1) the rotor shaft is formed by the beam elements and the rotational inertia and gyroscopic moment of the beam are taken into account, (2) the compressors and the turbines are simplified as disks, which is considered to be a mass of points concentrated in the center of a mass, and (3) bearings are considered as spring elements and have the same stiffness in all directions. Detailed information about beam 188 element can be found in reference [31]. The result obtained from a Campbell diagram shows that the critical speeds range from low to high order in the order of $264 \mathrm{rpm}(4.4 \mathrm{~Hz}), 768 \mathrm{rpm}(12.8 \mathrm{~Hz}), 2196(36.6 \mathrm{~Hz}), 2484$ $(41.4 \mathrm{~Hz}), 2916 \mathrm{rpm}(48.6 \mathrm{~Hz})$, and $4314 \mathrm{rpm}(71.9 \mathrm{~Hz})$. The Campbell diagram and corresponding mode shapes are shown in Figure 2.

The transient response of a rotor system is analyzed and calculated in MATLAB. To analyze the response of the lowpressure rotor, a divided finite element model is established with a few details neglected. The low-pressure compressor shaft consists of 17 elements, and there are 18 nodes in the whole shaft, as shown in Figure 3.

The typical elements of the rotor system are the disk and elastic shaft, and the position of the disk and support bearings is the key point. Based on the typical structure, the motion equation of the finite element model is established. 
The equation of motion of a rigid disk is

$$
\left\{\begin{array}{l}
{\left[M_{d}\right] \ddot{q}_{y}+\left[G_{d}\right] \dot{q}_{z}=Q_{y}} \\
{\left[M_{d}\right] \ddot{q}_{z}-\left[G_{d}\right] \dot{q}_{y}=Q_{z}}
\end{array}\right.
$$

In the equation, $Q_{y}$ and $Q_{z}$ are generalized forces and $q_{y}$ and $q_{z}$ are generalized displacement.

The equation of motion of an elastic shaft is

$$
\left\{\begin{array}{l}
{\left[M_{T}+M_{R}\right] \ddot{q}_{y}+[G] \dot{q}_{z}+[K] q_{y}=Q_{y},} \\
{\left[M_{T}+M_{R}\right] \ddot{q}_{z}-[G] \dot{q}_{y}+[K] q_{z}=Q_{z}}
\end{array}\right.
$$

In the equation, $\left[M_{T}\right]$ is the translational inertia matrix, $\left[M_{R}\right]$ is the rotational inertia matrix, $[G]$ is the rotation matrix, and $[K]$ is the stiffness matrix. Since the inertia matrix is symmetrical, it can be arranged in the following format.

$$
[M]^{(i)}=\left[M_{T}+M_{R}\right]^{(i)}=\left[\begin{array}{ll}
{\left[m_{11}\right]^{(i)}} & {\left[m_{12}\right]^{(i)}} \\
{\left[m_{21}\right]^{(i)}} & {\left[m_{22}\right]^{(i)}}
\end{array}\right] .
$$

The dynamic equations of the rotor are integrated, and the schematic of the inertia matrix assembly is shown as follows.

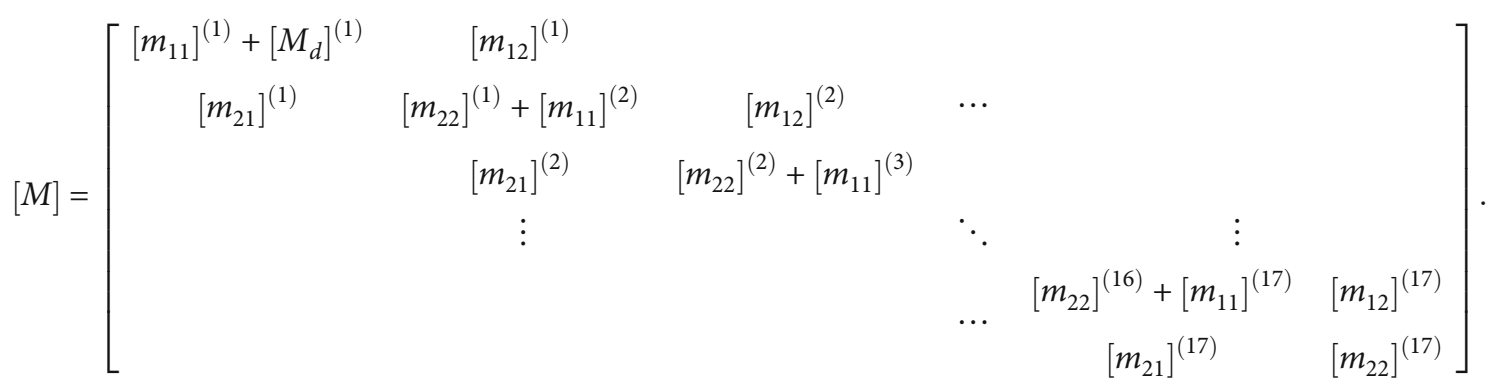

In the equation, $[M]$ is the inertia matrix of the lowpressure rotor system. The superscript (1) denotes element 1 , and the subscript $d$ denotes the disk. $[G]$ and $[K]$ can be obtained in a similar way.

Generalized forces must consider the effects of gravity and initial imbalance. For the low-pressure rotor model, gravity exists at nodes 1 and 17, and gravity is

$$
\left\{\begin{array}{l}
Q_{y L}(2 \times 1-1)=-m_{1 L} g \\
Q_{y L}(2 \times 17-1)=-m_{17 L} g .
\end{array}\right.
$$

In the equation, $m_{1 L}$ is the quality of the low-pressure compressor disk and $m_{17 L}$ is the quality of the low-pressure turbine disk. The numbers in brackets refer to the position of the elements in the corresponding vector.

After integrating the motion equations of the dual-rotor system, the boundary conditions are added, including the stiffness and damping introduced by the support bearings and intermediate bearing. The bearings are simplified as linear spring elements with a stiffness value of $5 \times 10^{7} \mathrm{~N} / \mathrm{m}$ and a damping value of $250 \mathrm{Ns} / \mathrm{m}$.

Rolling bearing supports exist at nodes 4,7 , and 18 of the rotor system. The supporting stiffness of the rolling bearing is added on the corresponding position element of $[K]$, and bearing damping is added to the corresponding position element of $[G]$.
When the sudden imbalanced load is considered, the imbalanced force contained in the dynamic equation of the rotor system will suddenly change as follows:

$$
\left\{\begin{array}{l}
Q_{y L}(2 \times 1-1)=m_{1} e \omega_{L}^{2} \sin \left(\omega_{L} t+\varnothing_{0}\right), \\
Q_{z L}(2 \times 1-1)=m_{1} e \omega_{L}^{2} \cos \left(\omega_{L} t+\varnothing_{0}\right) .
\end{array}\right.
$$

In the equation, $e$ is the eccentricity, $\omega_{L}$ is the rotation rate of the low-pressure shaft, and $\varnothing_{0}$ is the initial phase angle.

Through the above steps, the motion equation of the dual-rotor system can be determined as follows:

$$
[M] \ddot{q}+[G] \dot{q}+[K] q=[Q] .
$$

According to the model established above, the response characteristics of the low-pressure rotor under a sudden unbalanced excitation are analyzed.

The $4040 \mathrm{r} / \mathrm{min}$ is chosen as the working speed. The operation conditions are that (1) the rotor system loses its blade $2 \mathrm{~s}$ after the start of the operation, (2) the centroid of the blade is $0.5 \mathrm{~m}$ from the centroid of the fan, and (3) the lost mass is $3 \mathrm{~kg}$. The dynamic response of the low-pressure rotor under a sudden imbalanced load, solved by the Newmark- $\beta$ integral method, is shown in Figure 4.

There is no imbalance at the beginning of the system operation. When the system runs for $2 \mathrm{~s}$, the blade-loss 


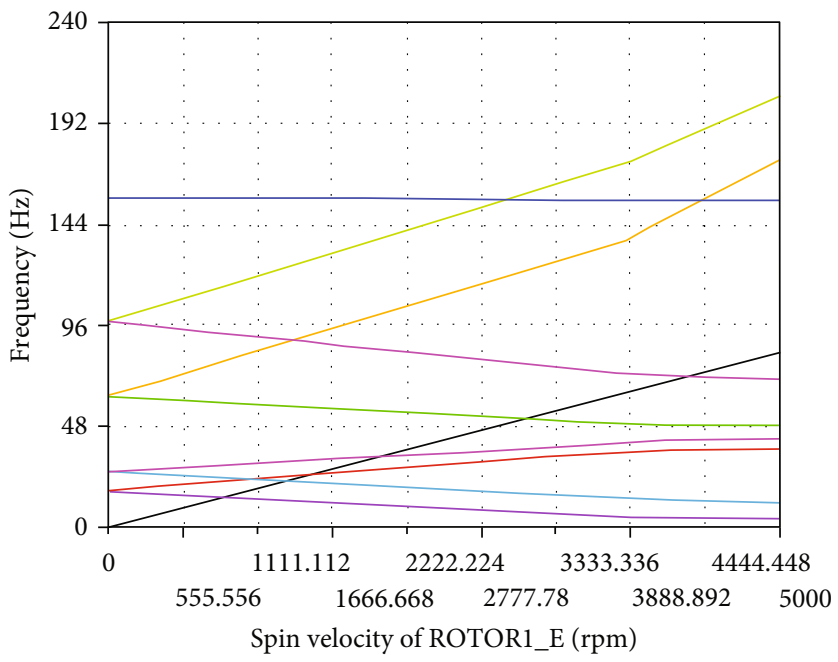

(a)

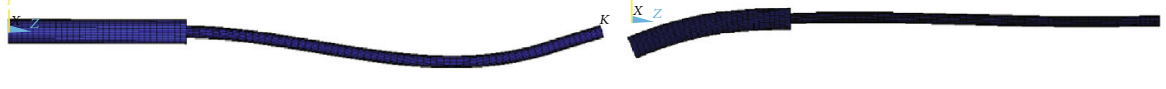

$4.4 \mathrm{~Hz}$

$12.8 \mathrm{~Hz}$

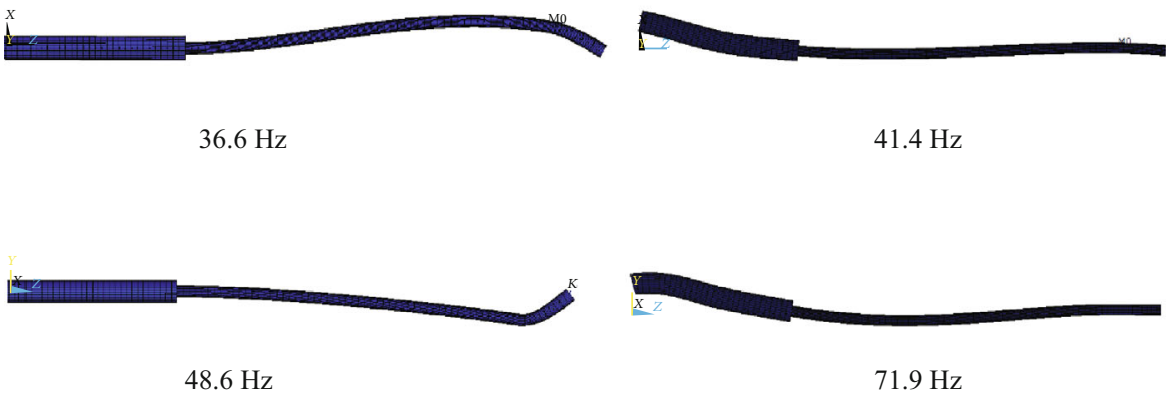

(b)

Figure 2: (a) Campbell diagram of a single-rotor system. (b) Mode shape of a single-rotor system.

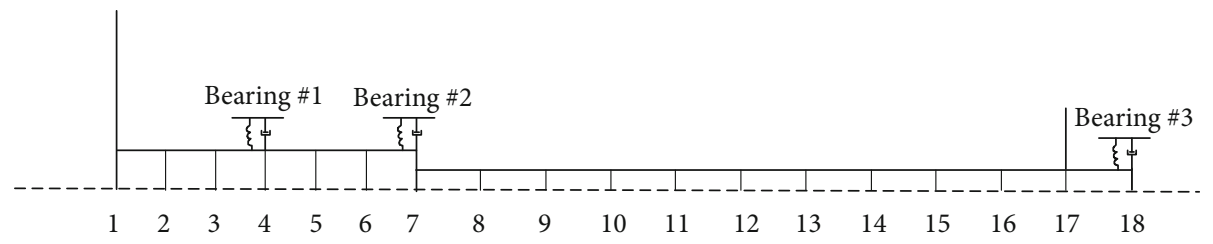

Figure 3: Finite element model of a low-pressure rotor.

accident occurs and the vibration response rises rapidly. After reaching the peak value, the vibration gradually decreases and enters the steady-state stage. In Figure 4(b), displacement is the distance from the initial position of the low-pressure compressor disk to the position after being stimulated by unbalanced loads, which is a scalar and always positive. The larger the displacement, the more obvious the response of the system under unbalanced load excitation is. The response trajectory of the rotor system is elliptical, and the imbalanced response of the transient peak value is larger than that of the steady-state stage. The whole system is stimulated by severe impact load when the blade is lost, which puts forward more stringent safety requirements for the structure of the aeroengine. It can be seen from Figure 4(c) 


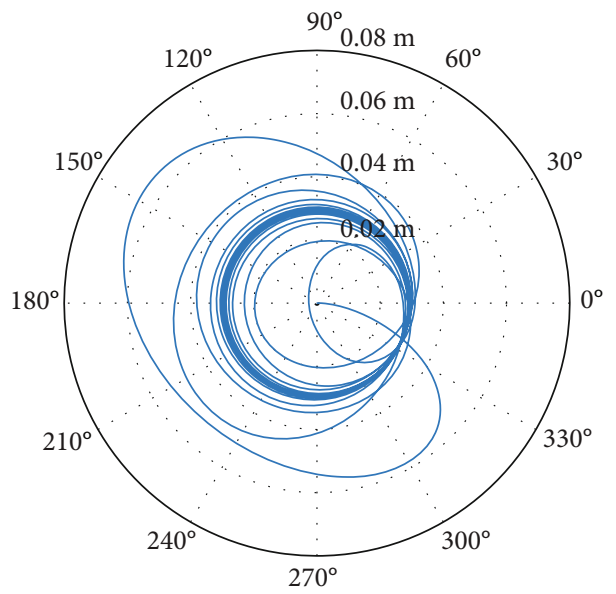

(a) Rotor orbit

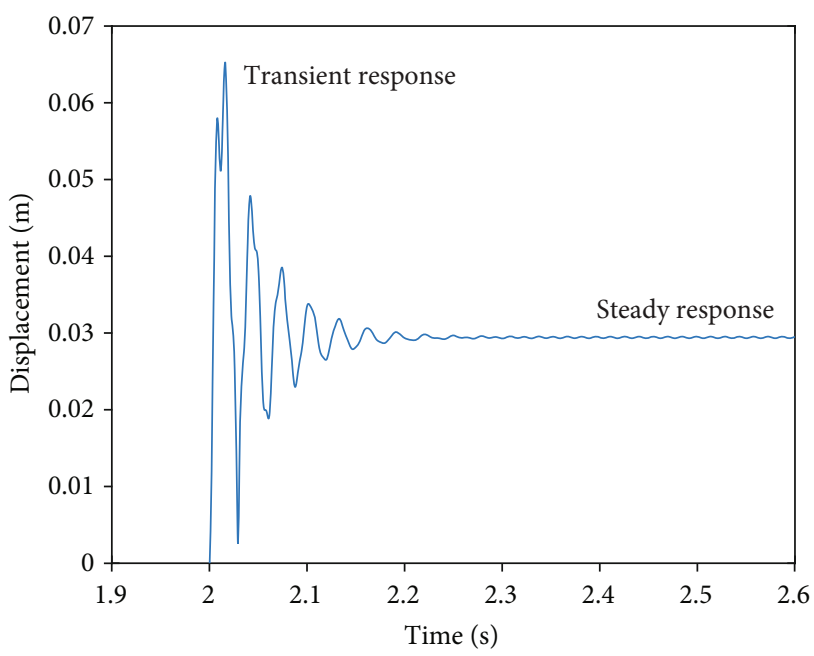

(b) Time waveform

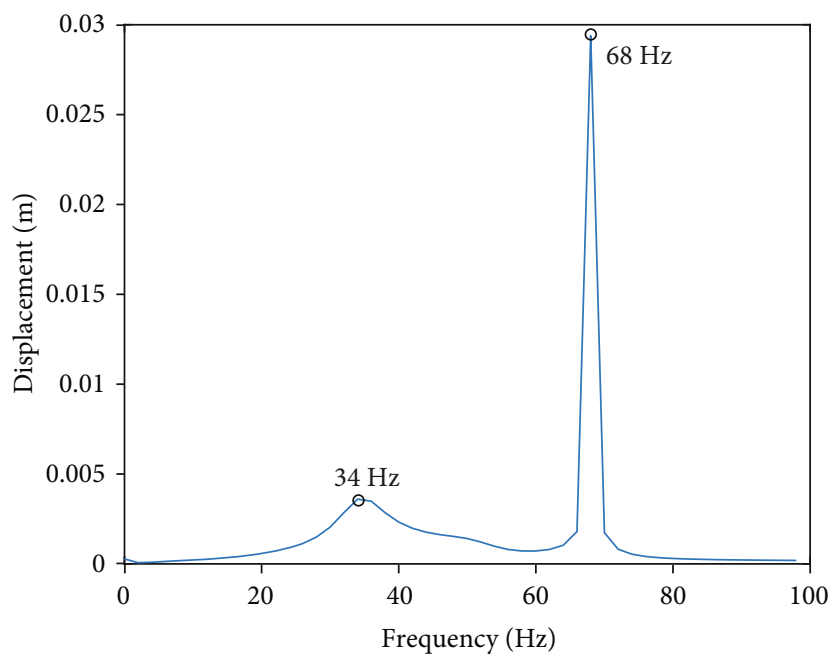

(c) Amplitude spectrum

FiguRE 4: Response of low-pressure compressor disk of low-pressure rotor system.

TABLE 2: Response value of a low-pressure compressor disk of a low-pressure rotor system.

\begin{tabular}{lcc}
\hline $\begin{array}{l}\text { Peak value of transient } \\
\text { response }(\mathrm{mm})\end{array}$ & $\begin{array}{c}\text { Amplitude of steady } \\
\text { response }(\mathrm{mm})\end{array}$ & $R_{u}$ \\
\hline 64.2 & 30.1 & 2.13 \\
\hline
\end{tabular}

that the frequency components $(34 \mathrm{~Hz}$ and $68 \mathrm{~Hz})$ are corresponding to the natural frequencies $(36.6 \mathrm{~Hz}$ and $71.9 \mathrm{~Hz})$ of the rotor system.

$R_{u}$ is the impact coefficient, which is also the ratio of the peak value of transient response to the amplitude of the steady-state response. The $R_{u}$ values are listed in Table 2 .

When the blade-loss accident occurs, the support reaction forces at each supporting bearing also change. By calculating the support reaction forces at each supporting point, it can be seen that the response characteristics of the support reaction forces are basically the same as that of the vibration response of the rotor. The response of the support reaction forces increases sharply when the sudden imbalance load occurs, and then, it decays to the steady state. The transient peak value is much larger than the steady-state value.

The response of support reaction forces is shown in Figure 5.

The support reaction forces of the three supporting bearings decrease as the distance from the fan disc increases. Support bearing \#1 is generally called the rear fan support bearing. Its support reaction force is much higher than that of other bearings. It is very vulnerable to damage, leading to safety accidents, which puts forward higher requirements for the safety of the support bearing and the bearing structure.

\section{Response of a Dual-Rotor System under a Sudden Imbalance Load}

Dual-rotor structure is a common structure in modern aeroengine. Because high- and low-pressure rotor systems 


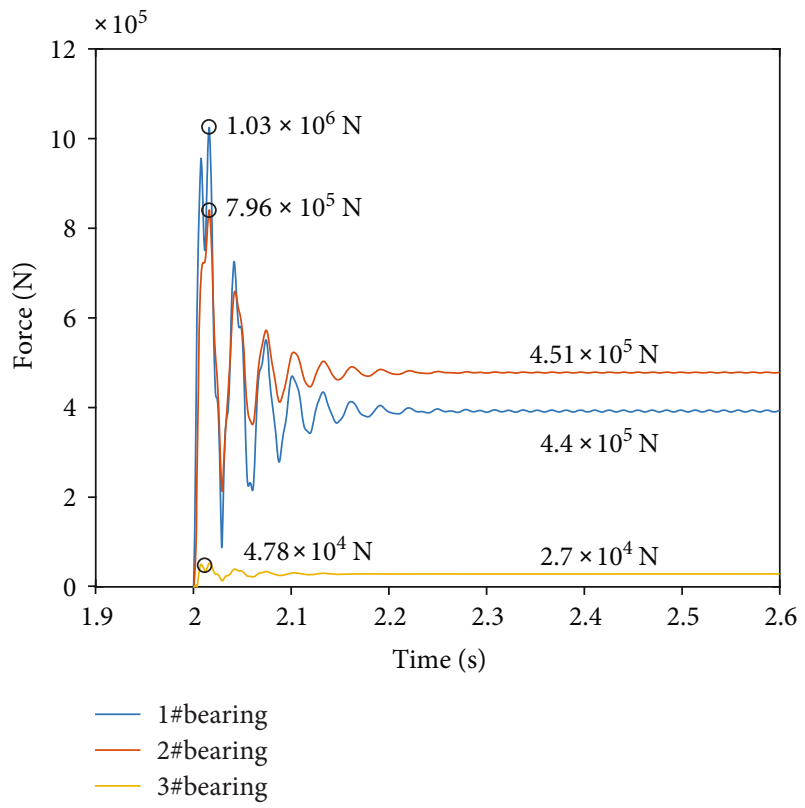

Figure 5: Reaction force of the support bearing of a low-pressure rotor system.

are coupled by intermediate bearings, it is necessary to establish finite element models including low-pressure rotor systems, high-pressure rotor systems, intermediate bearings, and other supporting structure when analyzing the response of aeroengine under sudden imbalanced loads. In this paper, the finite element model of the whole machine is established on the basis of the finite element model of the low-pressure rotor mentioned above.

To analyze the response of the high-pressure rotor, the divided finite element model is established with a few details neglected. The high-pressure compressor shaft consists of 17 elements, and there are 18 nodes in the whole shaft, just as Figure 6 shows.

The motion equation of the high-pressure rotor system is integrated, and the integration method is similar to that of the low-pressure rotor system. High-pressure compressor disk and high-pressure turbine disk are located at node 6 and 16, respectively. The gravity of disk is taken into account by the form of external load force. The expression is as follows:

$$
\begin{gathered}
Q_{y H}(2 \times 6-1)=-m_{6 H} g, \\
Q_{y H}(2 \times 16-1)=-m_{16 H} g .
\end{gathered}
$$

In the equation, $m_{6 H}$ is the quality of the highpressure compressor disk and $m_{16 H}$ is the quality of the high-pressure turbine disk. Combining the above equations, the motion equations of the dual-rotor system can be integrated as follows:

$$
[M] \ddot{q}+[G] \dot{q}+[K] q=[Q] .
$$

In the equation,

$$
\begin{aligned}
& {[M]=\left[\begin{array}{llll}
{\left[M_{L}\right]} & & & \\
& {\left[M_{H}\right]} & & \\
& & {\left[M_{L}\right]} & \\
& & & {\left[M_{H}\right]}
\end{array}\right] \text {, }}
\end{aligned}
$$

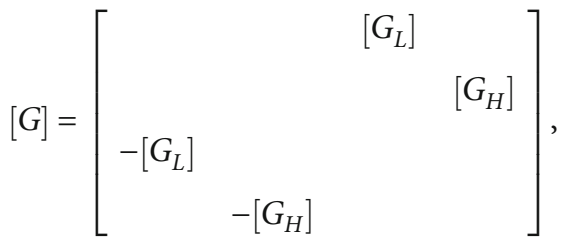

$$
\begin{aligned}
& {[K]=\left[\begin{array}{llll}
{\left[K_{L}\right]} & & & \\
& {\left[K_{H}\right]} & & \\
& & {\left[K_{L}\right]} & \\
& & & {\left[K_{H}\right]}
\end{array}\right] \text {, }} \\
& {[Q]=\left[\begin{array}{c}
Q_{y L} \\
Q_{y H} \\
Q_{z L} \\
Q_{z H}
\end{array}\right]} \\
& q=\left[\begin{array}{c}
q_{y L} \\
q_{y H} \\
q_{z L} \\
q_{z H}
\end{array}\right] \\
& q_{y L}=\left[\begin{array}{c}
u_{1 y} \\
\theta_{1 y} \\
\vdots \\
u_{18 y} \\
\theta_{18 y}
\end{array}\right] \text {, } \\
& q_{y H}=\left[\begin{array}{c}
u_{19 y} \\
\theta_{19 y} \\
\vdots \\
u_{36 y} \\
\theta_{36 y}
\end{array}\right] \text {. }
\end{aligned}
$$

The finite element model of the renumbered dualrotor system is shown in Figure 7.

After renumbering the finite element model and integrating the motion equations of the dual-rotor system, the boundary conditions are added, including the stiffness and damping introduced by the support bearings and intermediate bearing. The bearings are simplified as linear spring elements with a stiffness value of $5 \times 10^{7} \mathrm{~N} / \mathrm{m}$ and a damping value of $250 \mathrm{Ns} / \mathrm{m}$. 


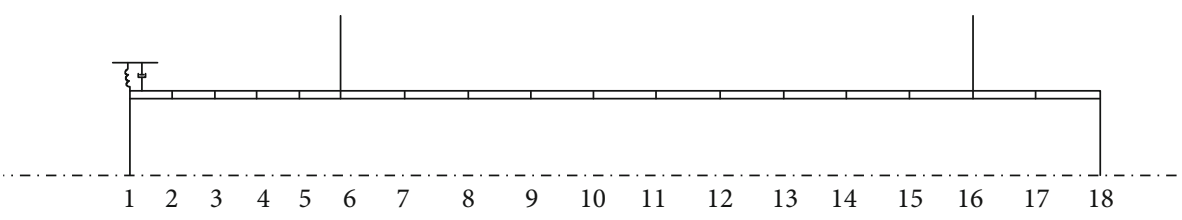

FIGURE 6: Finite element model of the high-pressure rotor.

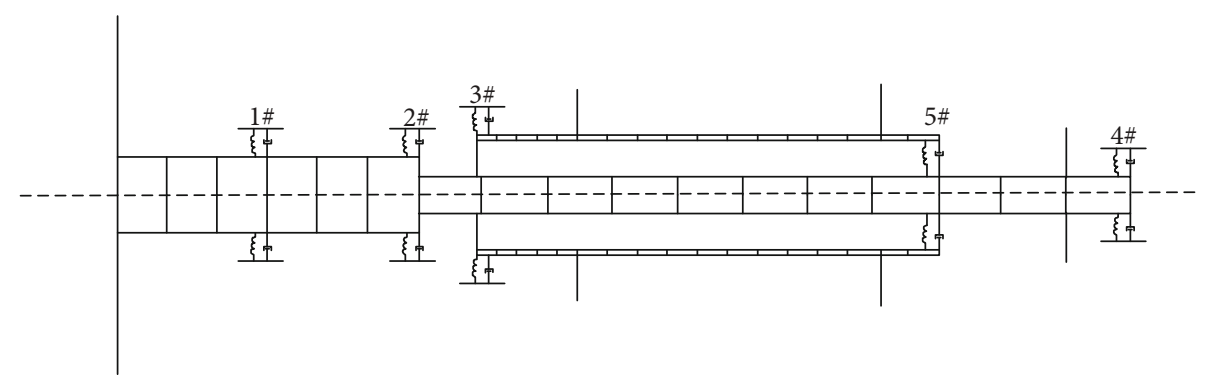

Figure 7: Finite element model of the dual-rotor system.

In the renumbered dual-rotor finite element model, the support bearings are located at nodes $4,7,18$, and 19. Taking stiffness matrix as an example, the stiffness matrix of a dualrotor system is

$$
[K]=\left[\begin{array}{llll}
{\left[K_{L}\right]} & & & \\
& {\left[K_{H}\right]} & & \\
& & {\left[K_{L}\right]} & \\
& & & {\left[K_{H}\right]}
\end{array}\right]
$$

where $\left[K_{L}\right]$ and $\left[K_{H}\right]$ are $36 \times 36$ matrices. No. 1 bearing is located at node 4 , so it will affect the stiffness value of element about node 4 in stiffness matrix. Relevant elements are labeled $(7,7)$ and $(79,79)$. Element positions are determined by the following rules:

$$
\begin{aligned}
(7,7)= & (2 \times \text { node number } 4-1,2 \times \text { node number } 4-1), \\
(79,79)= & (2 \times \text { node number } 4+72-1,2 \times \text { node number } 4 \\
& +72-1)
\end{aligned}
$$

The calculation of other bearings follows the same rules.

In order to introduce the influence of bearings into the dual-rotor system, the stiffness and the damping of the support bearings are added to elements $(7,7),(13,13)$, $(35,35),(37,37),(79,79),(85,85),(107,107)$, and $(109$, $109)$ of the stiffness matrix $[K]$ and rotation matrix $[G]$, respectively. The numbers in the parentheses represent the position of the elements in the corresponding matrix.

The intermediate bearings are located between nodes 15 and 36. It will affect the value of element about nodes 15 and 36 in stiffness matrix and rotation matrix. Assuming that the intermediate bearing is isotropic, the intermediate bearing is simplified to a linear spring element with a stiffness value of $5 \times 10^{7} \mathrm{~N} / \mathrm{m}$ and a damping value of $250 \mathrm{Ns} / \mathrm{m}$. According to the theory of stiffness coupling [32], the stiffness and the damping of the intermediate bearing are added to the elements $(29,29),(71,71),(101,101)$, and $(143,143)$ of the stiffness matrix $[K]$ and rotation matrix $[G]$, respectively, and subtracted from the elements $(29,71),(71,29)$, $(101,143)$, and $(143,101)$ of the stiffness matrix $[K]$ and rotation matrix $[G]$, respectively, which introduces the influence of the intermediate bearing into the dual-rotor system. Positions of the relevant elements are determined by the following rules:

$$
\begin{aligned}
(29,29)= & (2 \times \text { node number } 15-1,2 \times \text { node number } 15-1), \\
(101,101)= & (2 \times \text { node number } 15+72-1,2 \times \text { node number } 15 \\
& +72-1) .
\end{aligned}
$$

The calculation of other element positions follows the same rules.

Combined with the above steps, the motion equation of the dual-rotor system can be established.

The $4040 \mathrm{r} / \mathrm{min}$ is chosen as the working speed of the low-pressure rotor, and the rotation rate of the highpressure rotor is $6060 \mathrm{r} / \mathrm{min}$. The operation conditions are that (1) the rotor system loses its blade $2 \mathrm{~s}$ after the start of the operation, (2) the centroid of the blade is $0.5 \mathrm{~m}$ from the centroid of the fan, and (3) the lost mass is $3 \mathrm{~kg}$. The dynamic response of the low-pressure rotor under a sudden imbalanced load, solved by the Newmark- $\beta$ integral method, is shown in Figure 8.

There is no imbalance at the beginning of the system operation. When the system runs for $2 \mathrm{~s}$, the blade-loss accident occurs and the vibration response rises rapidly. After reaching the peak value, the vibration gradually decreases and enters the steady-state stage. The response trajectory of the rotor system is elliptical, and the unbalanced response 


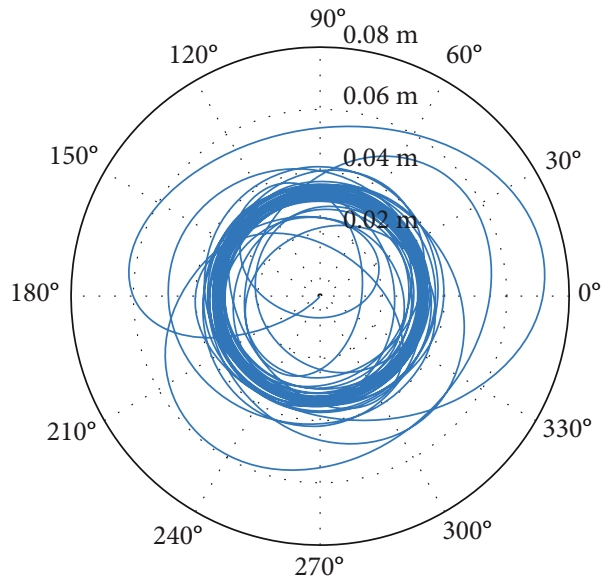

(a) Rotor orbit

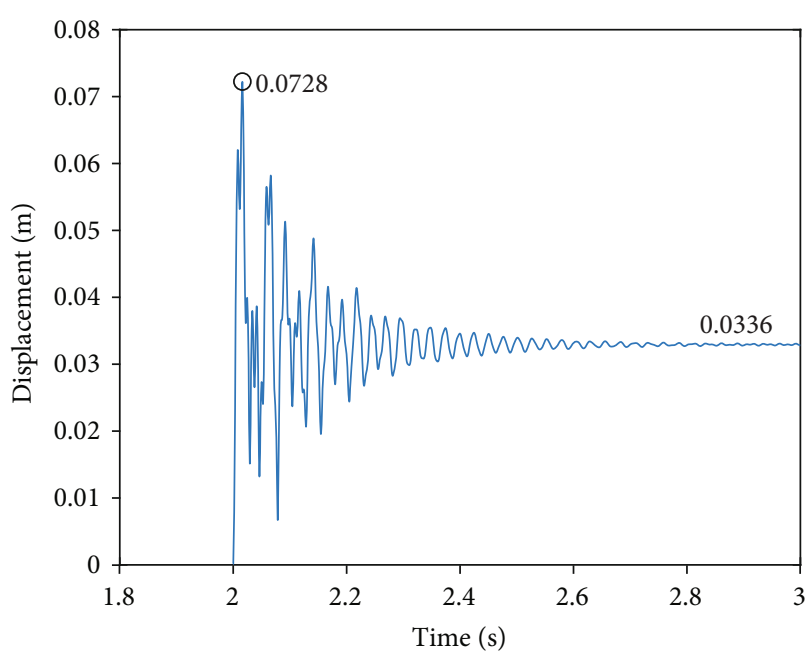

(b) Time waveform

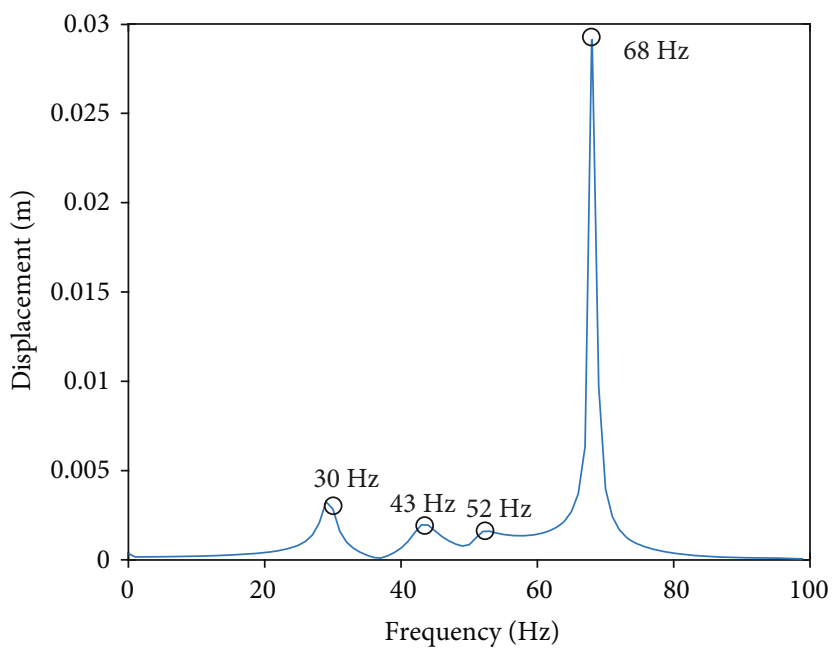

(c) Amplitude spectrum

FIGURE 8: Response of a fan disk of a dual-rotor system.

of the transient peak value is larger than that of the steadystate stage. The whole system is stimulated by a severe impact load when the blade is lost, which yields severe safety requirements for the structure of the aeroengine.

It can be seen that the response of the dual-rotor system has undergone a sudden sharp rise and then decay to stability. Owing to the coupling of high- and low-pressure rotors, the range of unstable rotational speed of the rotor is enlarged. Thus, the dynamic analysis of the whole dual-rotor system is needed. Moreover, compared with the single-rotor system, the dynamic response of the double-rotor system is more complex. It can be seen from Figure 8(c) that more frequency components appear in the response of the system, which is caused by the coupling of high- and low-pressure rotors in the dual-rotor structure. Because of the existence of intermediate bearings, both the support mode of the low-pressure rotor system and the corresponding natural frequency change. At the same time, the response of the high- and low-pressure rotor system will be mutually affected. The excitation from the low-pressure rotor system will also stimulate the response of the high-pressure rotor system, and the frequency component of the system response will reflect the dynamic characteristics of the high-pressure rotor. Calculating the dynamic response of the dual-rotor system, the displacement response of the low-pressure and high-pressure compressor and turbine disks are shown in Figure 9.

It can be seen that the displacement response of the highpressure turbine disk is only inferior to that of the lowpressure compressor disk due to the interaction between the high-pressure and low-pressure rotors in the twin-rotor system, which may lead to the rubbing of turbine blades and casings and the fracture of turbine blades. This is a problem that cannot be identified by analyzing the low-pressure rotor system alone. The transient peak value is much larger than the steady-state value, and the amplitude of the response is presented in Table 3 .

When the blade-loss accident occurs, the support reaction forces at each supporting bearing change accordingly. By calculating the support reaction forces at each supporting point, it can be seen that the response characteristics of the 


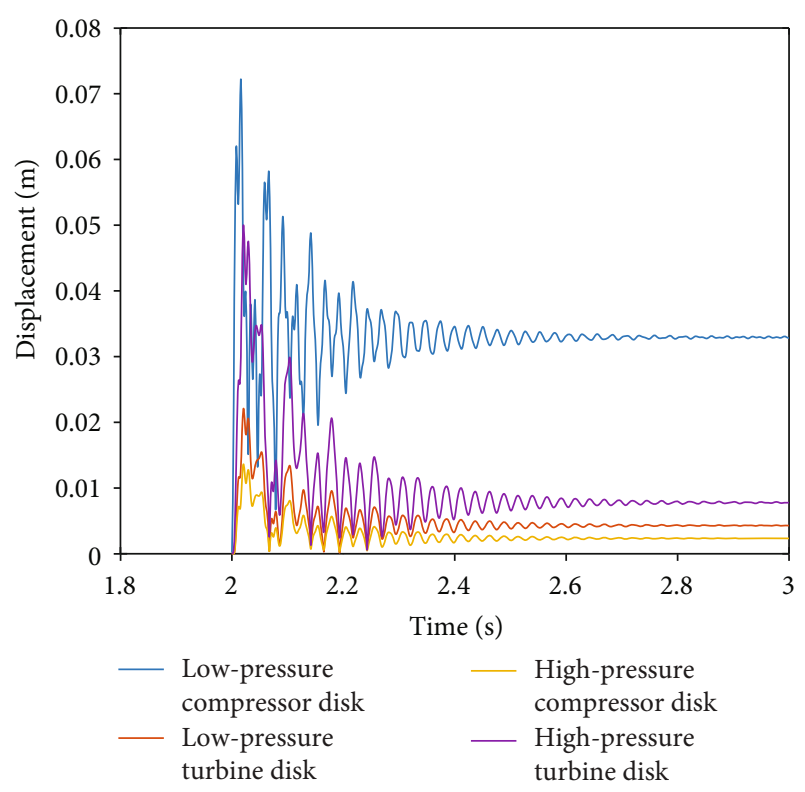

Figure 9: Displacement response of a dual-rotor system.

TABle 3: Displacement response of a dual-rotor system.

\begin{tabular}{lcc}
\hline Position & $\begin{array}{c}\text { Peak value of transient } \\
\text { response }(\mathrm{mm})\end{array}$ & $\begin{array}{c}\text { Amplitude of steady } \\
\text { response }(\mathrm{mm})\end{array}$ \\
\hline $\begin{array}{l}\text { Low-pressure } \\
\text { compressor disk }\end{array}$ & 72.8 & 33.6 \\
$\begin{array}{l}\text { Low-pressure } \\
\text { turbine disk }\end{array}$ & 22.4 & 4.5 \\
$\begin{array}{l}\text { High-pressure } \\
\text { compressor disk }\end{array}$ & 13.8 & 2.5 \\
$\begin{array}{l}\text { High-pressure } \\
\text { turbine disk }\end{array}$ & 50.7 & 8.3 \\
\hline
\end{tabular}

support reaction forces are basically the same as those of the rotor's vibration response. The response of the support reaction forces increases sharply when the sudden imbalance load occurs, and then, it decays to the steady state. The response of support reaction forces is shown in Figure 10.

The amplitude of the reaction force of different bearings is presented in Table 4.

The support reaction forces of the three supporting bearings decrease as the distance from the fan disc increases. The support bearing \#1 is generally called the rear fan support bearing. Its support reaction force is much higher than that of other bearings. It is very vulnerable to damage, leading to safety accidents, which yields higher requirements for the safety of the support bearing and bearing structure.

\section{Fusing Structure}

5.1. Fusing Structure Form. In the case of the FBO event, the rear support bearing of the fan will suffer a huge impact load and the excessive support reaction will cause bearing failure and serious safety accidents. A few protective structures are

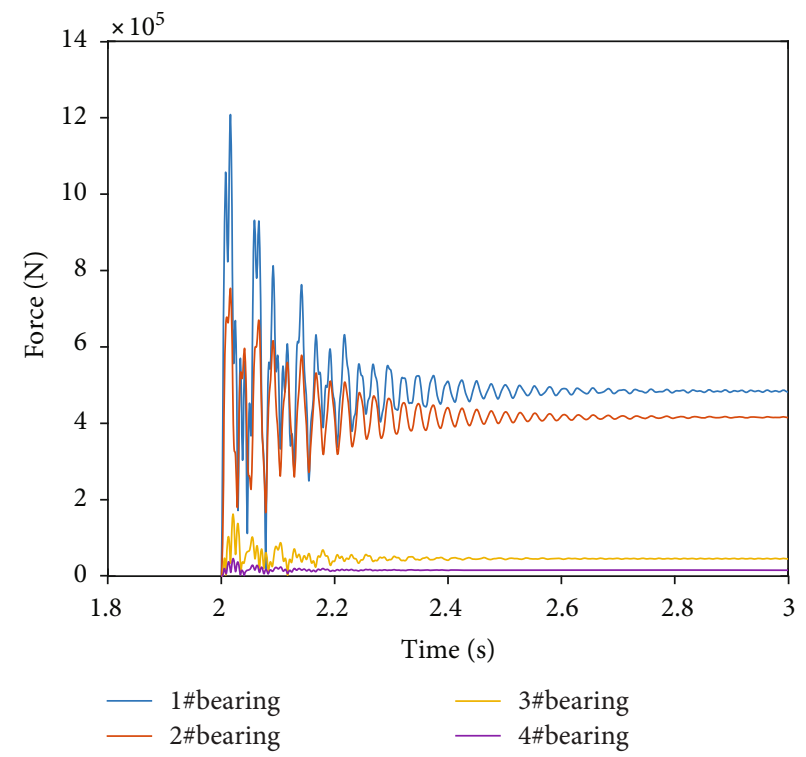

FIGURE 10: Reaction force of a dual-rotor system.

TABLE 4: Reaction force of support bearings.

\begin{tabular}{lcc}
\hline Position & $\begin{array}{c}\text { Peak value of transient response } \\
\left(\times 10^{5} \mathrm{~N}\right)\end{array}$ & $\begin{array}{c}\text { Amplitude of steady } \\
\text { response }\left(\times 10^{5} \mathrm{~N}\right)\end{array}$ \\
\hline$\# 1$ & 12.3 & 5.0 \\
$\# 2$ & 7.57 & 4.14 \\
$\# 3$ & 1.65 & 0.48 \\
$\# 4$ & 0.47 & 0.16 \\
\hline
\end{tabular}

used in the engine support structure. An effective way to reduce the load at the bearing is to reduce the support stiffness of the bearing, and the structure that implements this function is called fusing structure.

Figure 11 lists two easy-to-implement fusing structures, which actively invalidate the bearing or reduce the support stiffness of the bearings when the support reaction exceeds the set threshold.

Figure 11(a) shows the theory fractured fusing structure. A weak point is set on the support structure of bearing \#1, and the weak point will break under the huge impact load. The active failure of bearing \#1 changes the supporting structure of the rotor system and the dynamic characteristics of the rotor system. In Figure 11(b), compared with the complete failure of the fractured fusing structure, the variedstiffness fusing structure reduces the support stiffness of bearing \#1 after FBO incidents. In normal operation state, bearing \#1 is supported by an external shell with high stiffness connected by bolts. After the FBO incident, the bolt breaks and the rotor is supported by an inner shell with lower stiffness. The principle of the two schemes is the same. By actively reducing the stiffness of support bearing \#1 through fragile original parts, the impact load stimulated by a sudden load is reduced. 


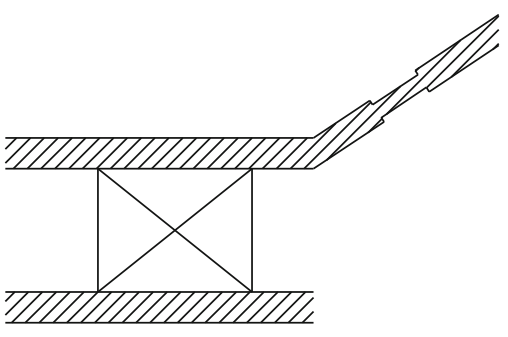

(a) Fractured fusing structure

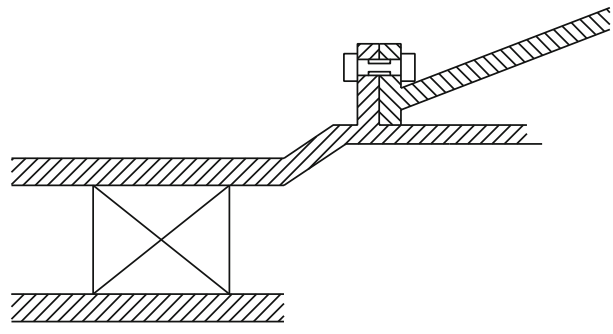

(b) Varied-stiffness fusing structure

FIgURE 11: Fusing structure.

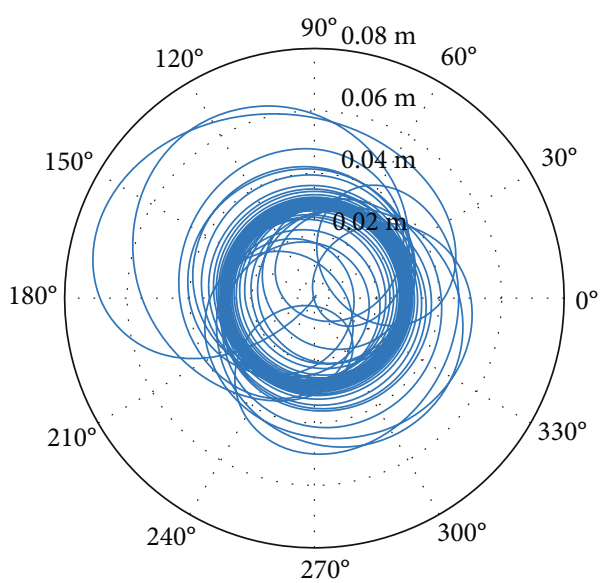

(a) Rotor orbit

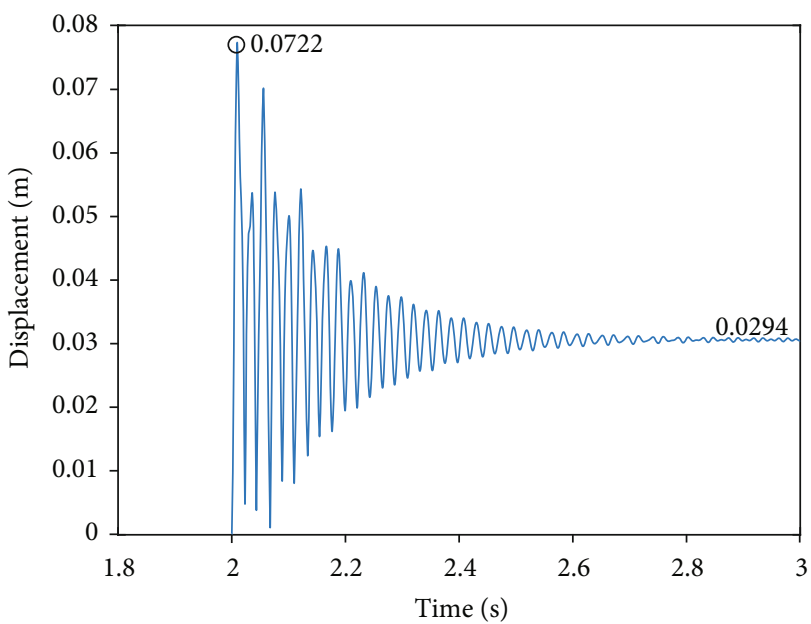

(b) Time waveform

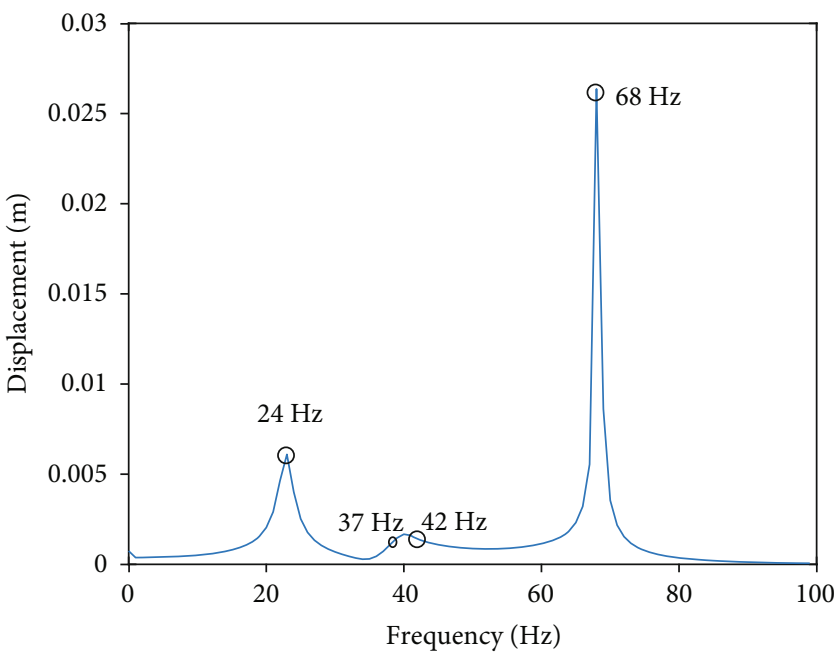

(c) Amplitude spectrum

FIGURE 12: Response of a rotor system with varied-stiffness fusing structure.

5.2. Response of a System with Varied-Stiffness Fusing Structure. A varied-stiffness fusing structure is an effective method to protect the rotor system. A dual-rotor system with varied-stiffness fusing structure is analyzed under the working condition as follows. The $4040 \mathrm{r} / \mathrm{min}$ is chosen as the working speed of the low-pressure rotor, and the highpressure rotor has a rotation rate of $6060 \mathrm{r} / \mathrm{min}$. The opera- tion conditions are that (1) the rotor system loses its blade $2 \mathrm{~s}$ after the start of operation, (2) the centroid of the blade is $0.5 \mathrm{~m}$ from the centroid of the fan, (3) the lost mass is $3 \mathrm{~kg}$, and (4) the fractured fusing structure is excited to reduce the support stiffness to $2 \times 10^{7} \mathrm{~N} / \mathrm{m}$ when the support reaction force of the rear fan reaches $6.5 \times 10^{5} \mathrm{~N}$. The dynamic response of the low-pressure compressor disk under 
TABLE 5: Response value of a dual-rotor system with varied-stiffness fusing structure.

\begin{tabular}{lcc}
\hline Position & $\begin{array}{c}\text { Peak value of } \\
\text { transient response }\end{array}$ & $\begin{array}{c}\text { Amplitude of steady } \\
\text { response }\end{array}$ \\
\hline $\begin{array}{l}\text { Fusing structure } \\
\text { activated }\end{array}$ & $77.2 \mathrm{~mm}$ & $29.4 \mathrm{~mm}$ \\
$\begin{array}{l}\text { Fusing structure not } \\
\text { activated }\end{array}$ & $72.8 \mathrm{~mm}$ & $33.6 \mathrm{~mm}$ \\
Relative deviation & $6.04 \%$ & $12.5 \%$ \\
\hline
\end{tabular}

TABle 6: Natural frequency of a dual-rotor system with variedstiffness fusing structure.

\begin{tabular}{lccc}
\hline Position & $\begin{array}{c}\text { Natural } \\
\text { frequency } \Omega 1\end{array}$ & $\begin{array}{c}\text { Natural } \\
\text { frequency } \Omega 2\end{array}$ & $\begin{array}{c}\text { Natural } \\
\text { frequency } \Omega 3\end{array}$ \\
\hline $\begin{array}{l}\text { Fusing structure } \\
\text { activated }\end{array}$ & $24 \mathrm{~Hz}$ & $37 \mathrm{~Hz}$ & $42 \mathrm{~Hz}$ \\
$\begin{array}{l}\text { Fusing structure } \\
\text { not activated }\end{array}$ & $30 \mathrm{~Hz}$ & $43 \mathrm{~Hz}$ & $52 \mathrm{~Hz}$ \\
Relative deviation & $20 \%$ & $14 \%$ & $19 \%$ \\
\hline
\end{tabular}

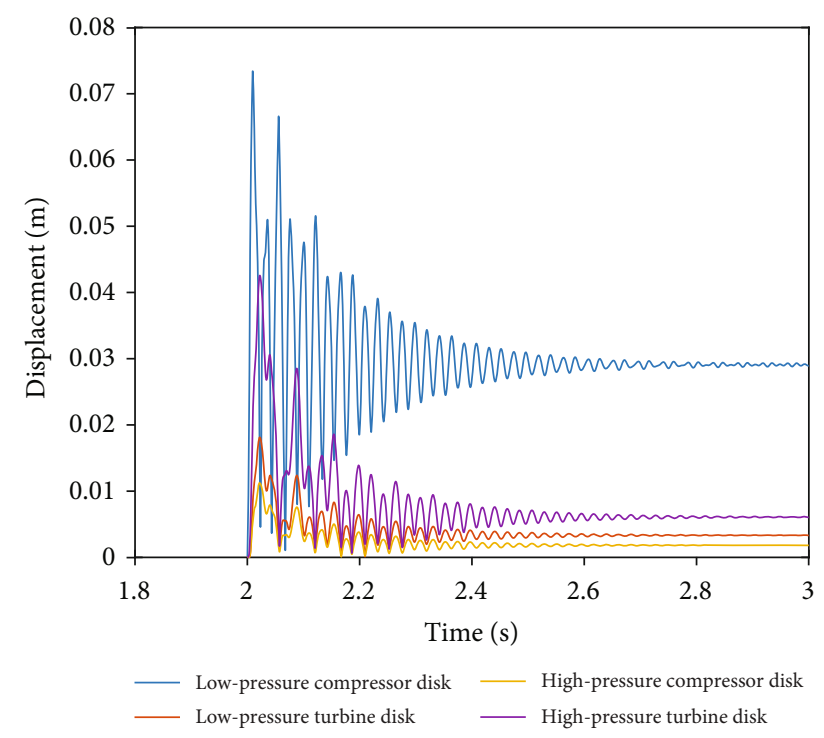

Figure 13: Displacement response of a dual-rotor system with varied-stiffness fusing structure.

a sudden unbalanced load, solved by the Newmark- $\beta$ integral method, is shown in Figure 12.

There is no imbalance when the system just starts the operation. When the system runs for $2 \mathrm{~s}$, the blade-loss accident occurs, the fusing structure is activated, and the vibration response rises rapidly. After reaching the peak value, the vibration gradually decreases and the system enters the steady-state stage. The response trajectory of the rotor system is elliptical, and the imbalanced response of the transient peak value is larger than that of the steady-state stage.

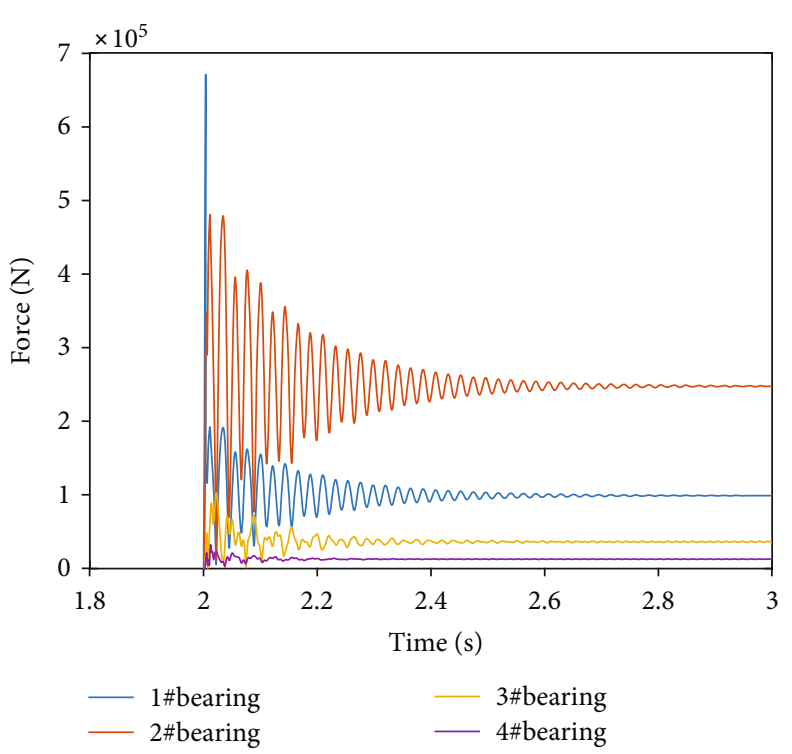

Figure 14: Reaction force of a rotor system with varied-stiffness fusing structure.

TABLE 7: Response value of a dual-rotor system with varied-stiffness fusing structure.

\begin{tabular}{|c|c|c|c|}
\hline \multicolumn{2}{|c|}{ Bearing number } & $\begin{array}{c}\text { Peak value of } \\
\text { transient response }\end{array}$ & $\begin{array}{l}\text { Amplitude of steady } \\
\text { response }\end{array}$ \\
\hline \multirow{2}{*}{$\# 1$} & $\begin{array}{l}\text { With fusing } \\
\text { structure }\end{array}$ & $6.64 \times 10^{5} \mathrm{~N}$ & $1.1 \times 10^{5} \mathrm{~N}$ \\
\hline & $\begin{array}{l}\text { Without fusing } \\
\text { structure }\end{array}$ & $12.3 \times 10^{5} \mathrm{~N}$ & $5.0 \times 10^{5} \mathrm{~N}$ \\
\hline \multirow{2}{*}{$\# 2$} & $\begin{array}{l}\text { With fusing } \\
\text { structure }\end{array}$ & $4.57 \times 10^{5} \mathrm{~N}$ & $2.31 \times 10^{5} \mathrm{~N}$ \\
\hline & $\begin{array}{l}\text { Without fusing } \\
\text { structure }\end{array}$ & $7.6 \times 10^{5} \mathrm{~N}$ & $4.1 \times 10^{5} \mathrm{~N}$ \\
\hline \multirow{2}{*}{ \#3 } & $\begin{array}{l}\text { With fusing } \\
\text { structure }\end{array}$ & $1.02 \times 10^{5} \mathrm{~N}$ & $0.36 \times 10^{5} \mathrm{~N}$ \\
\hline & $\begin{array}{l}\text { Without fusing } \\
\text { structure }\end{array}$ & $1.7 \times 10^{5} \mathrm{~N}$ & $0.5 \times 10^{5} \mathrm{~N}$ \\
\hline \multirow{2}{*}{$\# 4$} & $\begin{array}{l}\text { With fusing } \\
\text { structure }\end{array}$ & $0.32 \times 10^{5} \mathrm{~N}$ & $0.13 \times 10^{5} \mathrm{~N}$ \\
\hline & $\begin{array}{l}\text { Without fusing } \\
\text { structure }\end{array}$ & $0.5 \times 10^{5} \mathrm{~N}$ & $0.2 \times 10^{5} \mathrm{~N}$ \\
\hline
\end{tabular}

Owing to the existence of varied-stiffness fusing structure, the peak value of the transient response of the rotor system increases. The response amplitude decreases when the system enters the steady-state stage, which has a positive influence on the engine's windmill condition. The response of the low-pressure compressor disk of the rotor system with and without the activated varied-stiffness fusing structure is given in Table 5.

The frequency component of the response under these conditions is shown in Table 6. 


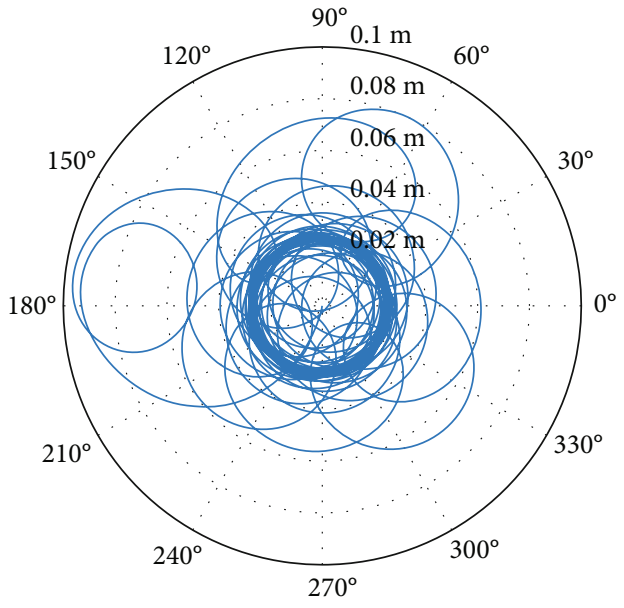

(a) Rotor orbit

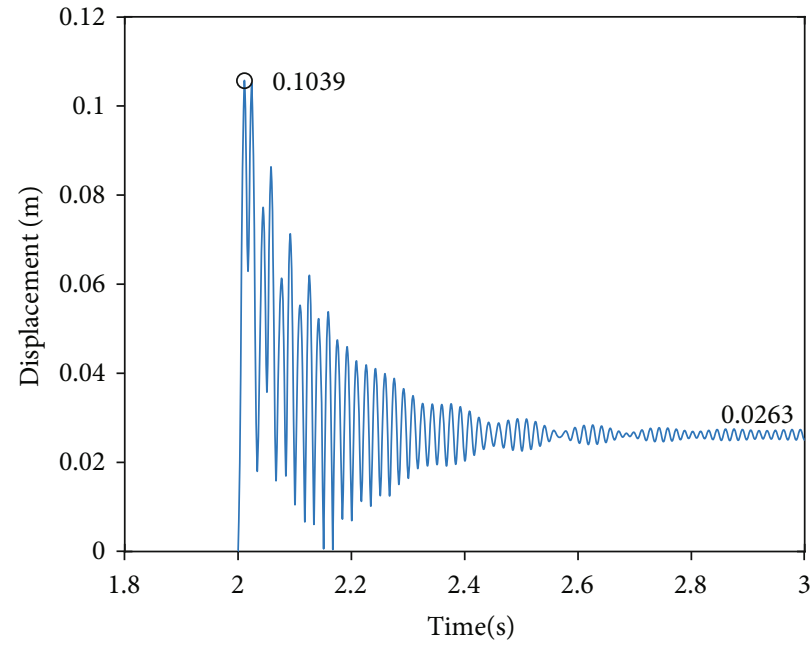

(b) Time waveform

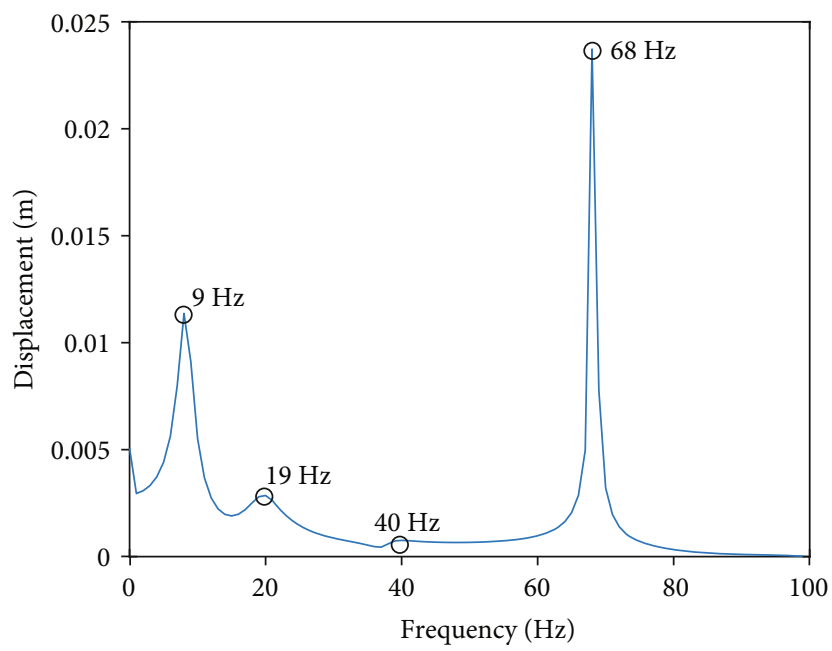

(c) Amplitude spectrum

FIGURE 15: Response of the system with fractured fusing structure.

It can be seen that varied-stiffness fusing structure can decrease the natural frequency of the rotor system, which is conducive to the safety of the engine.

The displacement response of the dual-rotor system is shown in Figure 13.

When the blade-loss accident occurs, the support reaction force at each supporting bearing changes as well. By calculating the support reaction force at each supporting point, it can be seen that the response characteristics of the support reaction forces are basically the same as those of the vibration response of the rotor. The response of support reaction forces is shown in Figure 14.

The reaction forces of the dual-rotor system under the condition with and without the activated fusing structure are shown in Table 7.

The support reaction forces of the four supporting bearings decrease as the distance from the fan disc increases. The support reaction force of the rear fan support bearings is much higher than that of other bearings. Compared with the rotor system without the fusing structure, it can be seen that
TABLE 8: Response value of a dual-rotor system with fractured fusing structure.

\begin{tabular}{lcc}
\hline Position & $\begin{array}{c}\text { Peak value of } \\
\text { transient response } \\
(\mathrm{mm})\end{array}$ & $\begin{array}{c}\text { Amplitude of } \\
\text { steady response } \\
(\mathrm{mm})\end{array}$ \\
\hline $\begin{array}{l}\text { Fusing structure activated } \\
(\mathrm{mm})\end{array}$ & 103.9 & 26.3 \\
$\begin{array}{l}\text { Fusing structure not } \\
\text { activated (mm) }\end{array}$ & 72.8 & 33.6 \\
Relative deviation (\%) & $42.7 \%$ & $21.7 \%$ \\
\hline
\end{tabular}

(1) when the reaction force exceeds the set threshold, the varied-stiffness fusing structure is activated and the support stiffness is decreased, making the reaction force of bearing \#1 reduced dramatically by approximately $46 \%$ of transient response, avoiding damage to bearing \#1 


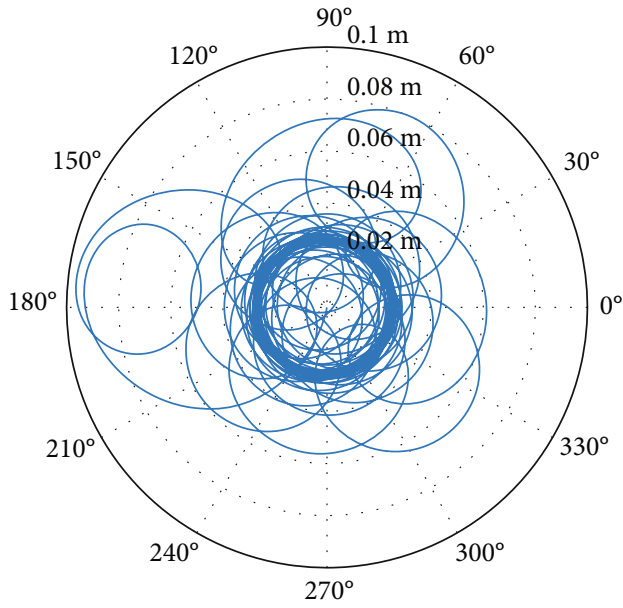

(a) $k=0 \mathrm{~N} / \mathrm{m}$

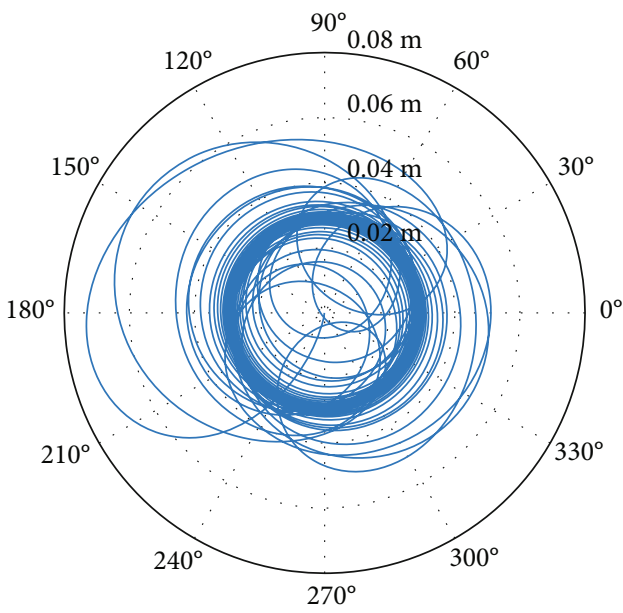

(c) $k=2 \times 10^{7} \mathrm{~N} / \mathrm{m}$

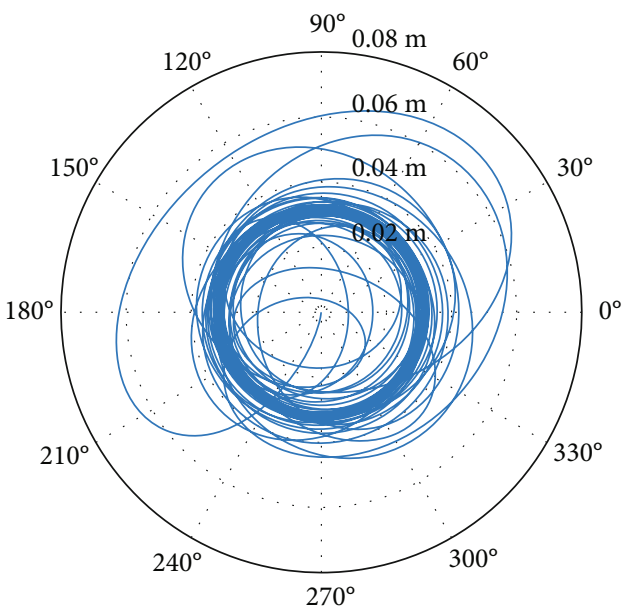

(e) $k=4 \times 10^{7} \mathrm{~N} / \mathrm{m}$

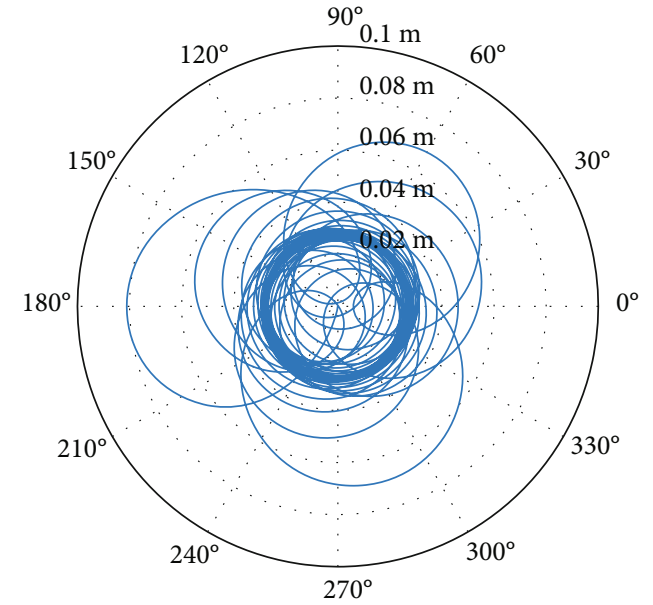

(b) $k=1 \times 10^{7} \mathrm{~N} / \mathrm{m}$

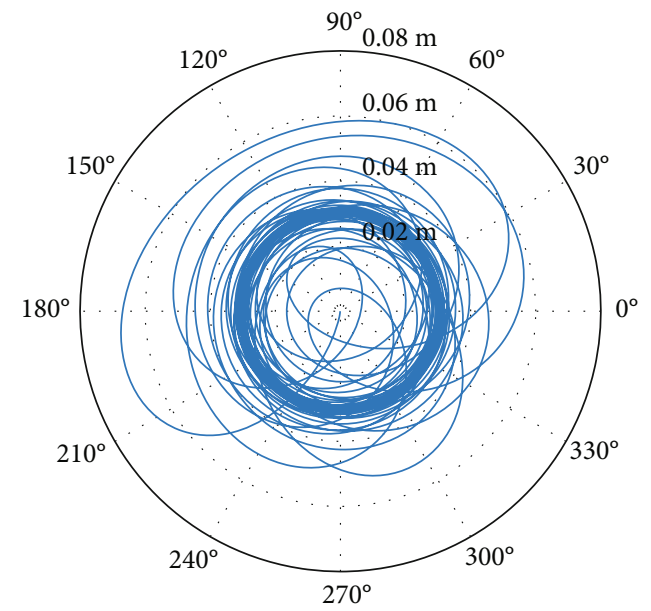

(d) $k=3 \times 10^{7} \mathrm{~N} / \mathrm{m}$

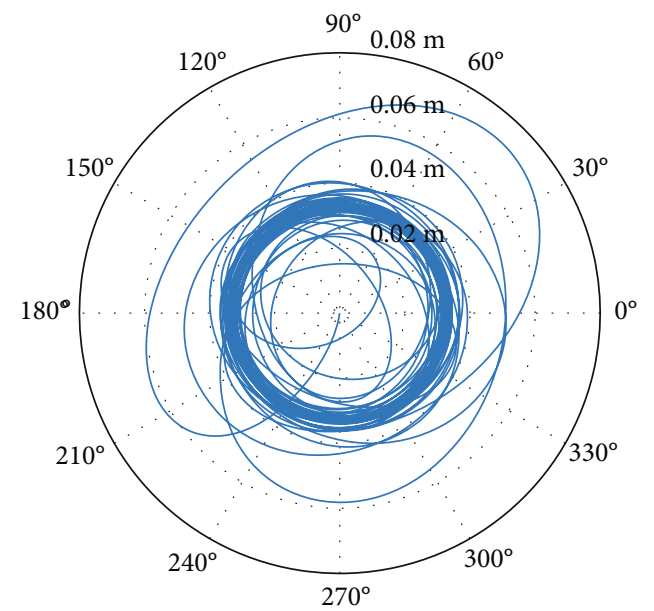

(f) $k=5 \times 10^{7} \mathrm{~N} / \mathrm{m}$

FIGURE 16: Response trace under different residual stiffness of bearing \#1.

(2) the whole level of displacement response of the dualrotor system is decreased basically according to the response of the four disks. In addition, the natural frequencies also decrease, which has a positive effect when the system undergoes a deceleration process
5.3. Weakening Degree of Support Stiffness of Bearing \#1. In conclusion, the fusing design can improve the safety and reliability of the system in the event of the FBO accident. However, the fusion design will lead to sudden changes in the support stiffness and other dynamic problems. The fractured 


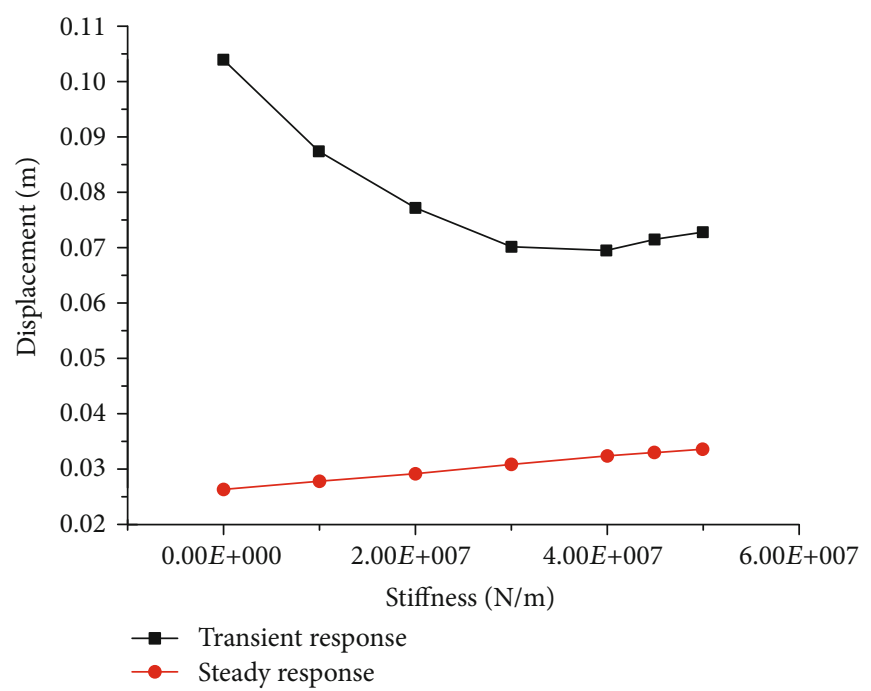

(a) Low-pressure compressor

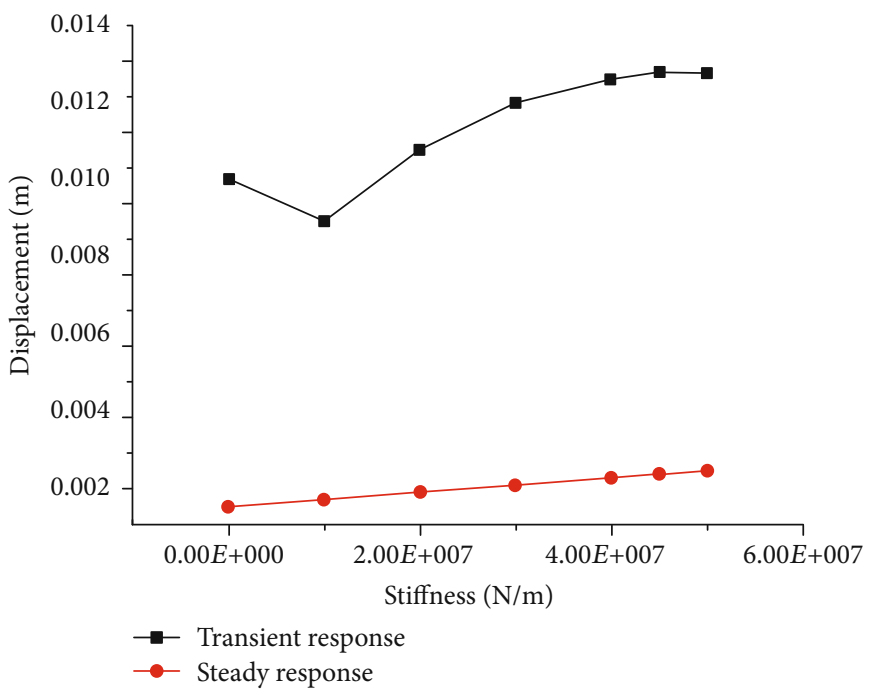

(c) High-pressure compressor

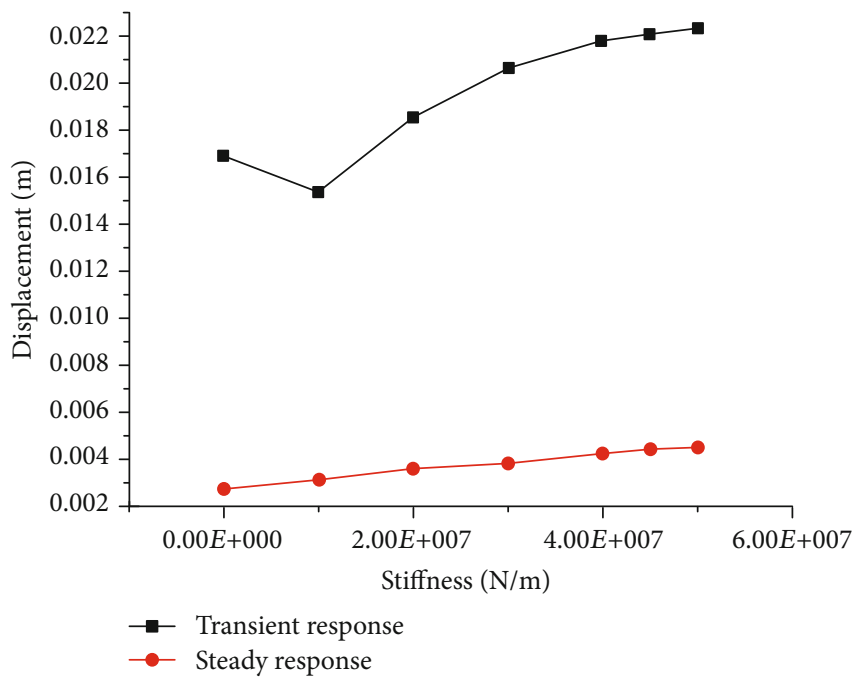

(b) Low-pressure turbine

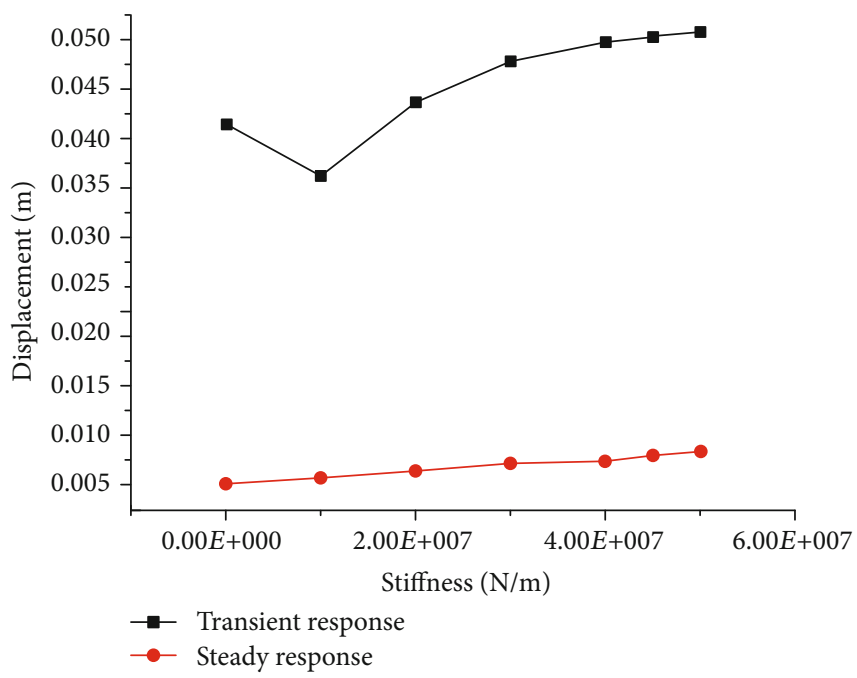

(d) High-pressure turbine

Figure 17: Displacement change with reduction in residual stiffness of bearing \#1.

fusing structure can be regarded as a special case of the varied stiffness fusing structure. Under the same calculation conditions, the fractured fusing structure is calculated and the dynamic response of the low-pressure compressor disk is shown in Figure 15.

Because of the fractured fusing structure, the peak value of the transient response of the rotor system increases. The responses of dual-rotor systems with and without the fractured fusing structure are shown in Table 8.

Owing to the activation of the fusing structure, the support form of the rotor changes and the peak value of transient response increases sharply, which would considerably affect the safety of the engine. Therefore, it is very important to study the influence on the response of rotor systems with fusing structures.

According to the principle of varied-stiffness fusing structure, the support stiffness of bearing \#1 will be weakened when the fused structure takes effect. The design of the weakened support stiffness will considerably affect the response amplitude of the rotor system. In this paper, the simulation analysis of the dual-rotor system is carried out under different designed residual stiffness values. The response of the rotor system with varying residual stiffness is shown in Figure 16.

The residual stiffness of bearing \#1 has a significant effect on the displacement response of the dual-rotor system. It can be seen that with the reduction of the residual stiffness of \#1 bearing, the shape of the response trace changes from the ellipse to the petal form. Considering the response of four disks mentioned above, the relationship between residual stiffness and response amplitude is shown in Figure 17.

It can be seen that with the decrease in the stiffness of bearing \#1, the response at the steady state decreases linearly. However, the peak value of transient response does not always reduce like the trend of that of the steady stage. The transient response would meet its lowest point and then increase with the reduction of the stiffness. The lowest points of transient response at different positions are not equal. 


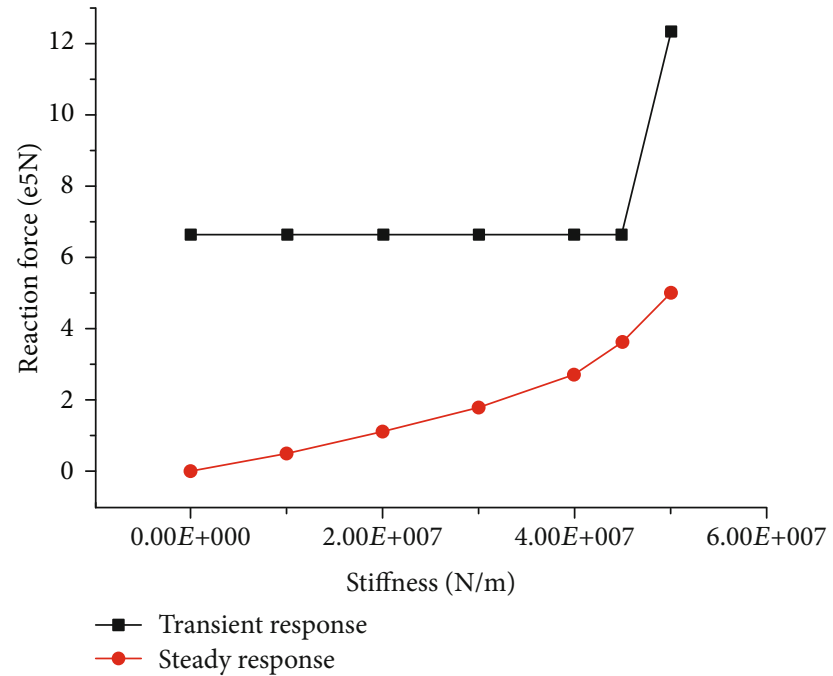

(a) Bearing \#1

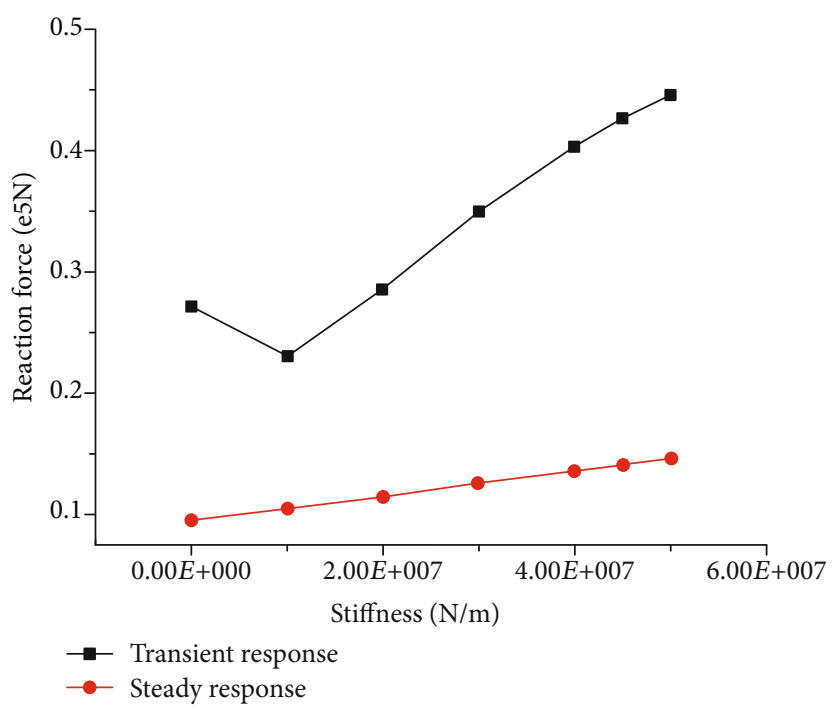

(c) Bearing \#3

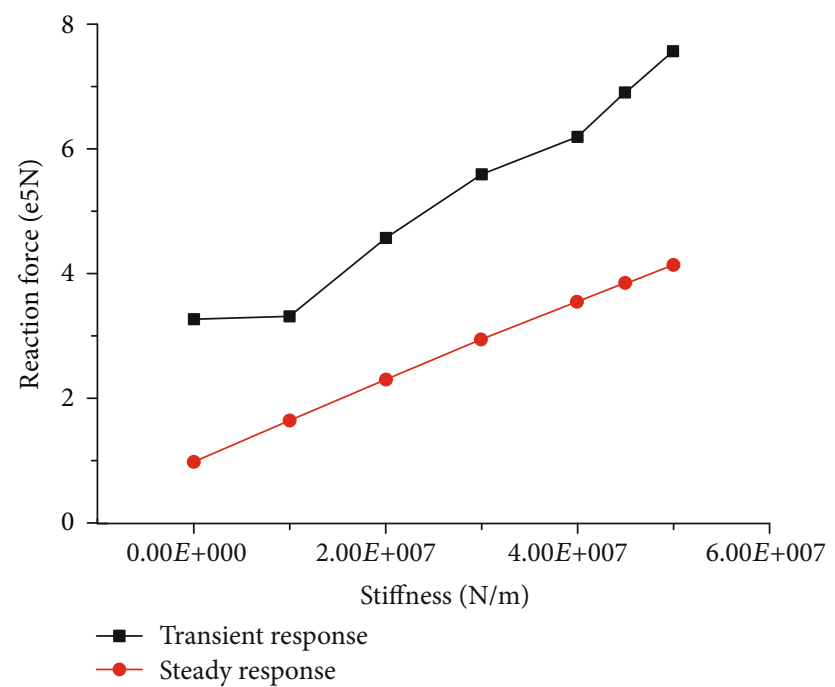

(b) Bearing \#2

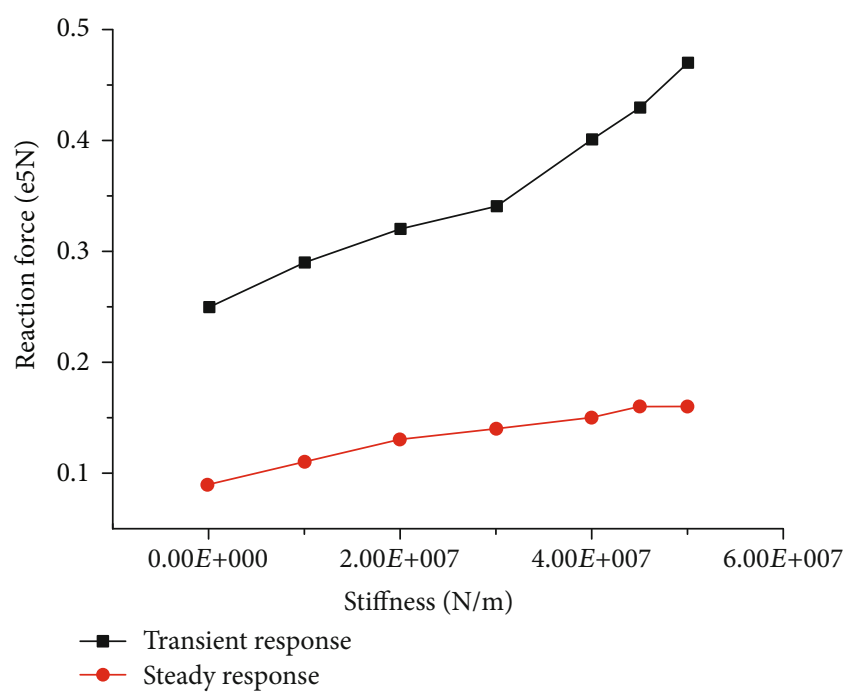

(d) Bearing \#4

FIGURE 18: Reaction force change with reduction in residual stiffness of bearing \#1.

Because the response at the low-pressure compressor disk will be the largest, the stiffness at $4 \times 10^{7} \mathrm{~N} / \mathrm{m}$ is chosen as a better design point in this case. The residual stiffness of bearing \#1 has a significant effect on the reaction force of the dual-rotor system. The relationship between the residual stiffness and the response amplitude is shown in Figure 18.

It can be seen that with the reduction of the stiffness of bearing \#1, the reaction force of different bearings decreases both in the transient and steady stages. The reaction force of \#1 shows that the fusing structure can reduce the load in the FBO event by approximately $46 \%$.

\section{Conclusion}

In this paper, the dynamic response characteristics of the dual-rotor system under the impact excitation of FBO events are analyzed and studied. Principal research and simulation analysis are carried out on the protection measures of aeroengine impact load for the fusing structure, and the effect of the key bearing stiffness on the dynamic performance with fusing structure is studied. The main conclusions are as follows:

(1) The dynamic model of a high-speed flexible cantilever rotor is established, and it can be used to effectively calculate the dynamic response of the rotor under the impact load. The characteristics of the transient and steady-response stages are analyzed, and the reaction forces of support bearings are calculated

(2) The finite element dynamic model of the dual-rotor system is established, and the dynamic response of 
the system under impact load is calculated. The sudden imbalanced impact load aggravates the dynamic response of the system, and the peak value of the transient response is much larger than the amplitude of the steady response. The reaction force of the rear fan support bearing may exceed the bearing capacity. The difference between the dual-rotor analysis and the single-rotor analysis is studied. The frequency components of the response of the dual-rotor system are more complex, and the dynamic response of the high-pressure turbine is also considerable, which cannot be covered by the single-rotor system analysis

(3) The working principle and dynamic response characteristics of the fusing structure are simulated and analyzed. When the external load reaches the preset failure load of the bearing, the fan rear support bearing will fail actively or the supporting stiffness of the bearing will be reduced. The simulation results show that the fusing structure can effectively reduce the large imbalanced response amplitude of the dualrotor system and reduce the critical rotation of the system to ensure the safety of the system in the deceleration process. The dynamic response of the two fusing structures in FBO events is simulated and analyzed. The results show that the varied-stiffness fusing structure can avoid the large increase in transient response peak value

\section{Data Availability}

The data used to support the findings of this study are available from the corresponding author upon request.

\section{Conflicts of Interest}

The authors declare that there is no conflict of interest regarding the publication of this paper.

\section{Acknowledgments}

This paper is based on the foundation of paper "Transient dynamic response of the aero-engine dual-rotor system under the blades loss load," in which the establishment of the finite element model of a dual-rotor system and unbalanced response of the system are discussed, but the frequency components and system characteristics of the response are not analyzed, the similarities and differences of the response of a single-rotor system and a double-rotor system are not comparatively analyzed, and the influence of fusing structure on the system response is not analyzed. In this paper, the finite element model of the rotor system is refined. The response of the system under a sudden unbalanced load and the reaction force of bearing are analyzed. The influence of the fusing structure on the response of the system is also studied. This work was supported by the National Science and Technology Major Project (2017-IV-0006-0043) and the National Natural Science Foundation of China (Grant number 51605218).

\section{References}

[1] C. Ma, L. Liu, L. Gang, C. Wei, and Z. Zhao, "Transient dynamic response of the aero-engine dual-rotor system under the blades loss load," in The Proceedings of the 2018 Asia-Pacific International Symposium on Aerospace Technology(APISAT2018), Chengdu, China, 2019.

[2] P. Yu, D. Zhang, Y. Ma, and J. Hong, "Dynamic modeling and vibration characteristics analysis of the aero-engine dual-rotor system with fan blade out," Mechanical Systems and Signal Processing, vol. 106, pp. 158-175, 2018.

[3] M. Heidari, D. L. Carlson, S. Sinha et al., "An efficient multidisciplinary simulation of engine fan-blade out event using MD Nastran," in 49th AIAA/ASME/ASCE/AHS/ASC Structures, Structural Dynamics, and Materials Conference, 16th AIAA/ASME/AHS Adaptive Structures Conference, 10th AIAA Non-Deterministic Approaches Conference, 9th AIAA Gossamer Spacecraft Forum, 4th AIAA Multidisciplinary Design Optimization Specialists Conference, Schaumburg, IL, USA, April 2008.

[4] S. K. Sinha and S. Dorbala, "Dynamic loads in the fan containment structure of a turbofan engine," Journal of Aerospace Engineering, vol. 22, no. 3, pp. 260-269, 2009.

[5] Y. Ma, Z. Liang, D. Zhang, W. Yan, and J. Hong, Experimental investigation on dynamical response of an overhung rotor due to sudden unbalance, ASME Turbo Expo2015: Turbine Technical Conference and Exposition, American Society of Mechanical Engineers, 2015.

[6] Federal Aviation Regulations Parts 33 airworthiness standards, Aircraft engines: FAA 14 CFR, Federal Aviation Administration, Washington, 1993.

[7] European Aviation Safety Agency, Certification Specifications for Engines, European Aviation Safety Agency, Germany, 2009.

[8] B. Yang, "Blade containment evaluation of civil aircraft engines," Chinese Journal of Aeronautics, vol. 26, no. 1, pp. 9-16, 2013.

[9] G. D. Roberts, D. M. Revilock, W. K. Binienda, W. Z. Nie, S. B. Mackenzie, and K. B. Todd, "Impact testing and analysis of composites for aircraft engine fan cases," Journal of Aerospace Engineering, vol. 15, no. 3, pp. 104-110, 2002.

[10] F. Chu and Z. Zhang, "Periodic, quasi-periodic and chaotic vibrations of a rub-impact rotor system supported on oil film bearings," International Journal of Engineering Science, vol. 35, no. 10-11, pp. 963-973, 1997.

[11] S. K. Sinha, "Dynamic characteristics of a flexible bladed-rotor with Coulomb damping due to tip-rub," Journal of Sound and Vibration, vol. 273, no. 4-5, pp. 875-919, 2004.

[12] H. Ma, C. Shi, Q. Han, and B. Wen, "Fixed-point rubbing fault characteristic analysis of a rotor system based on contact theory," Mechanical Systems and Signal Processing, vol. 38, no. 1, pp. 137-153, 2013.

[13] G. Genta, Dynamics of Rotating Systems, Springer Science \& Business Media, 2007.

[14] H. Dzenan, Mechanical loads on a turbofan engine structure at blade-off, Lulea University of Technology, Sweden, 2009.

[15] C. Lawrence, K. Carney, and V. Gallardo, "Simulation of aircraft engine blade-out structural dynamics," in NASA/TM2001-210957, Worldwide Aerospace Conference and Technology Showcase, Toulouse, France, September 2001.

[16] P. Kalinowski, O. V. Bargen, and R. Liebich, "Vibrations of rotating machinery due to sudden mass loss," in Proceedings 
of the 8th IFl'oMM, International Conference on Rotor Dynamics, Seoul, South Korea, 2010.

[17] F. A. Raffa and F. Vatta, "The dynamic stiffness method for linear rotor-bearing systems," Journal of Vibration and Acoustics, vol. 118, no. 3, pp. 332-339, 1996.

[18] H. Ma, F. Yin, Z. Wu, X. Tai, and B. Wen, "Nonlinear vibration response analysis of a rotor-blade system with blade-tip rubbing," Nonlinear Dynamics, vol. 84, no. 3, pp. 1225-1258, 2016.

[19] O. Grapis, V. Tamuzs, N. G. Ohlson, and J. Andersons, "Overcritical high-speed rotor systems, full annular rub and accident," Journal of Sound and Vibration, vol. 290, no. 3-5, pp. 910-927, 2006.

[20] S. K. Sinha, "Rotordynamic analysis of asymmetric turbofan rotor due to fan blade-loss event with contact-impact rub loads," Journal of Sound and Vibration, vol. 332, no. 9, pp. 2253-2283, 2013.

[21] B. Li, H. Ma, X. Yu, J. Zeng, X. Guo, and B. Wen, "Nonlinear vibration and dynamic stability analysis of rotor-blade system with nonlinear supports," Archive of Applied Mechanics, vol. 89, no. 7, pp. 1375-1402, 2019.

[22] L. Z. Yong, Dynamic Modeling and Nonlinear Vibration Research of Aero Engine Rotor System, Harbin Institute of Technology, Harbin, 2017.

[23] P. Bonello and P. Minh Hai, "A receptance harmonic balance technique for the computation of the vibration of a whole aero-engine model with nonlinear bearings," Journal of Sound and Vibration, vol. 324, no. 1-2, pp. 221-242, 2009.

[24] P. M. Hai and P. Bonello, "An impulsive receptance technique for the time domain computation of the vibration of a whole aero-engine model with nonlinear bearings," Journal of Sound and Vibration, vol. 318, no. 3, pp. 592-605, 2008.

[25] M. Ananda Rao, J. Srinivas, V. B. V. Rama Raju, and K. V. S. S. Kumar, "Coupled torsional-lateral vibration analysis of geared shaft systems using mode synthesis," Journal of Sound and Vibration, vol. 261, no. 2, pp. 359-364, 2003.

[26] V. Gerez, "Method for enabling operation of an aircraft turboengine with rotor unbalance," 1999, United States patent US 5974782.

[27] J. A. Kastl and R. M. Vondrell, "Bearing support fuse," 2002, United States patent US 6447248.

[28] E. Boratgis, "Turbine engine bearing support," 2001, United States Patent:6428269.

[29] J. W. Allen and K. F. Udall, "Turbofan with frangible rotor support," 2000, United States Patent: 6109022.

[30] K. V. Duyn, "Bearing support," 2006, United States Patent: 7097413.

[31] B. Xue, Optimization design of portal frame structures based on APDL, Southwest Jiaotong University, Chengdu, 2009.

[32] C. Jiang, Dynamic characteristics of dual rotor rolling bearing system, Harbin Institute of Technology, Harbin, 2017. 


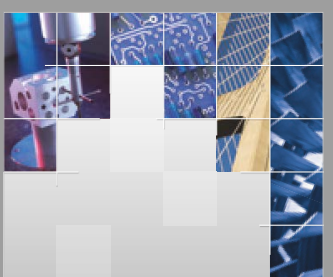

\section{Enfincering}
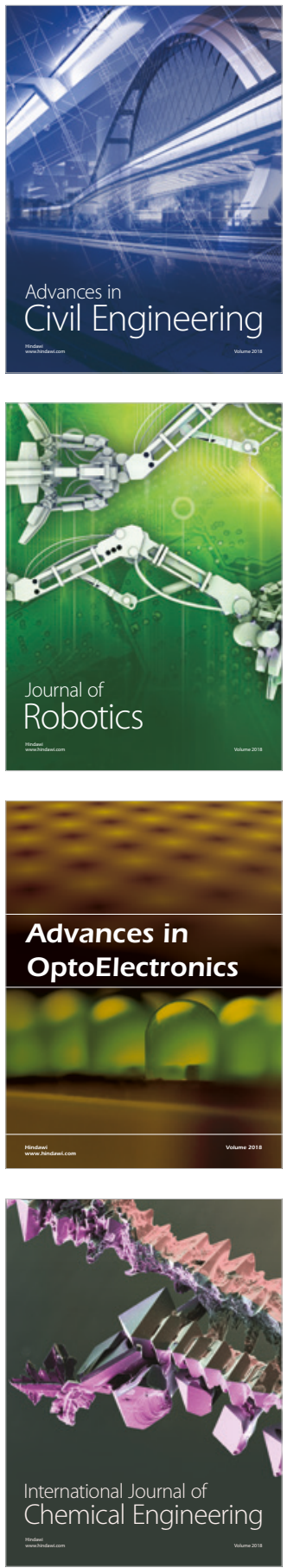

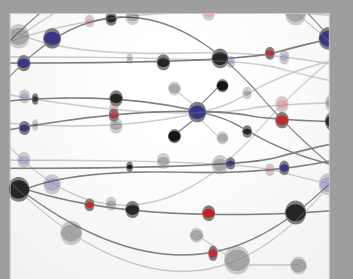

\section{Rotating \\ Machinery}

The Scientific World Journal

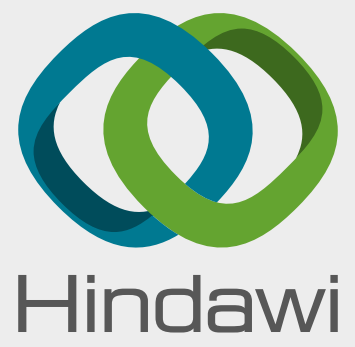

Submit your manuscripts at

www.hindawi.com
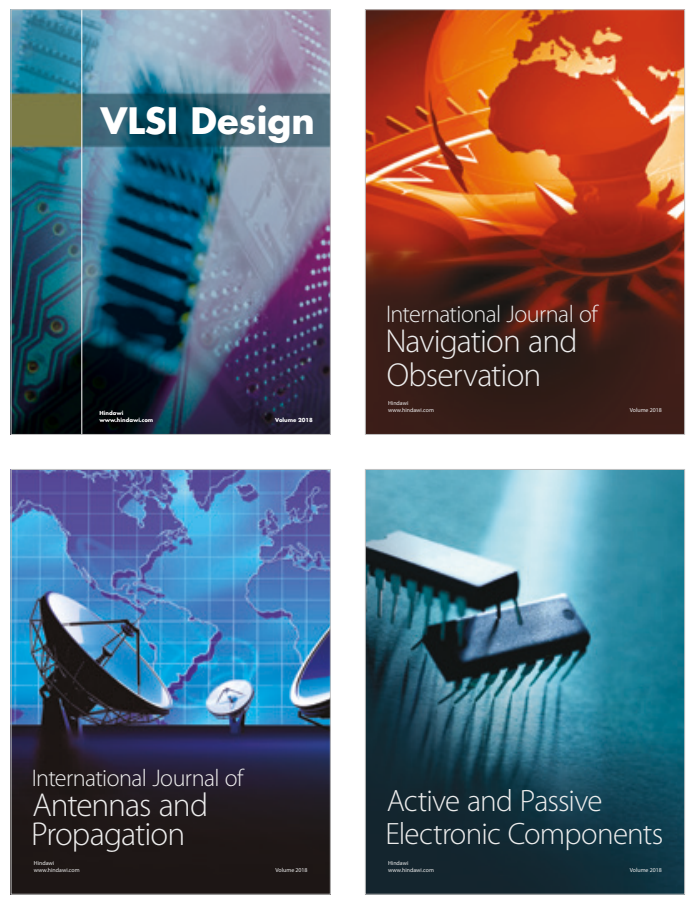
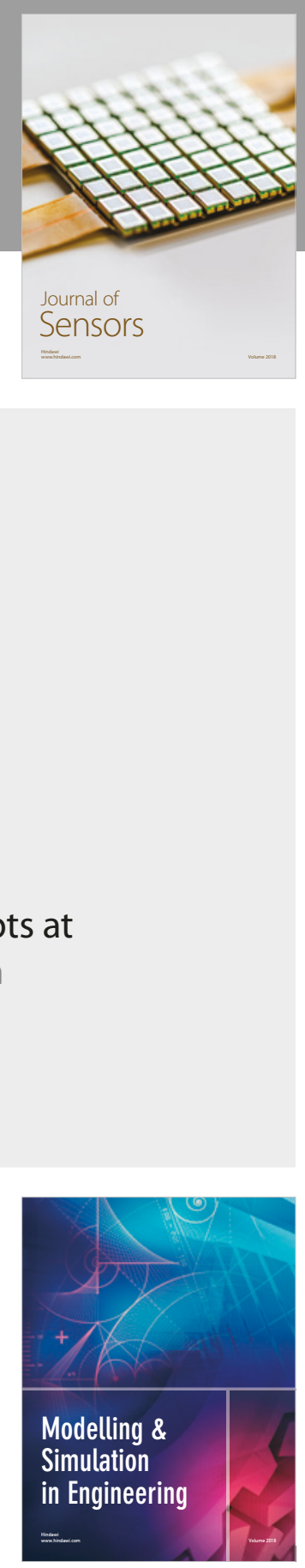

\section{Advances \\ Multimedia}
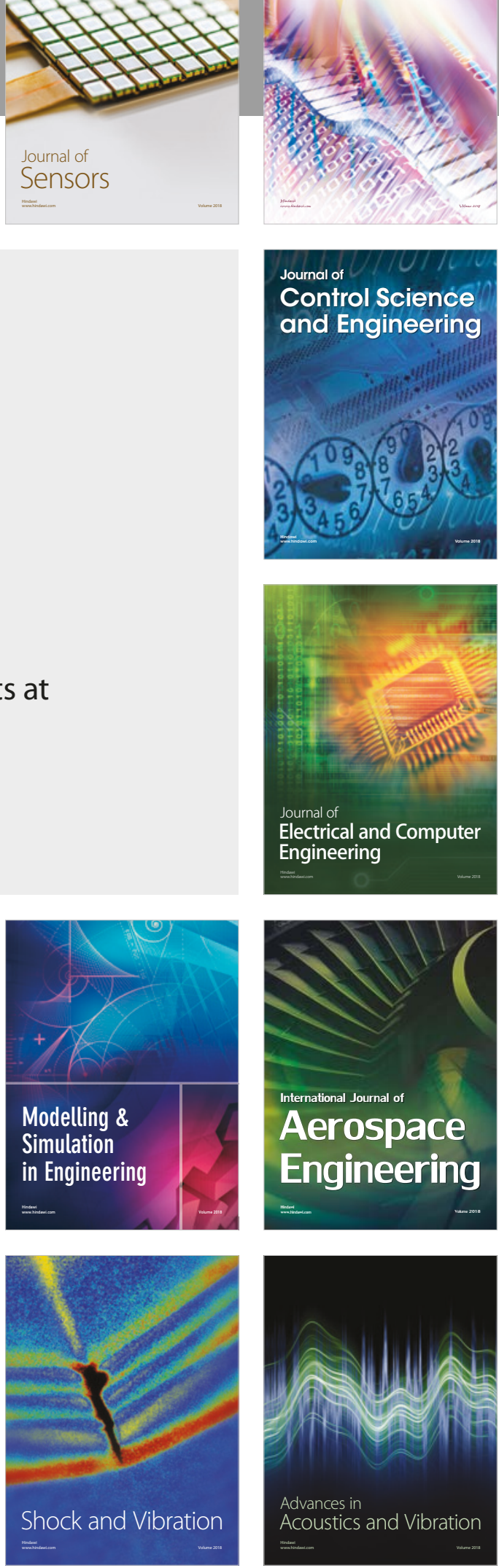